\title{
Potency density tensor inversion of complex body waveforms with time- adaptive smoothing constraint
}

\author{
Shinji Yamashita ${ }^{1}$, Yuji Yagi², Ryo Okuwaki ${ }^{2,3,4}$, Kousuke Shimizu1, Ryoichiro \\ $\operatorname{Agata}^{5}$, and Yukitoshi Fukahata ${ }^{6}$
}

${ }^{1}$ Graduate School of Science and Technology, University of Tsukuba, Tsukuba, Ibaraki 305-8572, Japan.

${ }^{2}$ Faculty of Life and Environmental Sciences, University of Tsukuba, Tsukuba, Ibaraki 305-8572, Japan.

${ }^{3}$ Mountain Science Center, University of Tsukuba, Tsukuba, Ibaraki 305-8572, Japan.

${ }^{4}$ COMET, School of Earth and Environment, University of Leeds LS2 9JT, UK.

${ }^{5}$ Japan Agency for Marine-Earth Science and Technology, 3173-25 Showa-machi, Kanazawa-ku, Yokohama 236-0001, Japan.

${ }^{6}$ Disaster Prevention Research Institute, Kyoto University, Uji, Kyoto 611-0011, Japan.

Corresponding author: Shinji Yamashita (ijnihsatihsamay@gmail.com)

\section{Keywords:}

- Inverse theory

- Waveform inversion

- Body waves

- Earthquake dynamics

- Earthquake source observations 


\section{Summary}

Large earthquakes are often accompanied by complex fault rupture, but it has been difficult to reliably estimate such a complex rupture process with conventional waveform analysis tools due to modelling errors originated from limited accuracy of the fault geometry. Recently, a potency density tensor inversion method has been developed to solve this problem; allowing any types of faulting mechanism on an assumed model plane, the method replaces the modelling error of fault orientation with that of fault location, which is much less serious in the teleseismic waveform inversion. Thus, the method has successfully unveiled earthquake source processes with geometrically complex fault rupture. However, the method imposes the same strength of smoothing constraint on all the basis slip components irrespective of possible changes of slip direction during the rupture. This leads to excessive smoothing to a slip component with large amplitude, which results in biased estimates of a rupture process. In this study, we propose a timeadaptive smoothing constraint that dynamically adjusts the smoothness intensity inversely proportional to the amplitude for each basis slip function. Through a numerical experiment assigning an input model involving a drastic change in the focal mechanism (reverse, strike-slip and normal faulting) during the rupture, we find that the time-adaptive smoothing constraint solves the problem of excessive smoothing to the dominant slip component, and the spatiotemporally non-uniform rupture episodes with different focal mechanisms are successfully reproduced. To evaluate the feasibility and effectiveness of the time-adaptive smoothing constraint, we apply the method to the teleseismic body waves of the 2002 Denali fault and the 2008 Wenchuan earthquakes, which involve complex fault ruptures with changing focal mechanisms. We find that the developed method well captures the focal mechanism transition in space and time from reverse to strike-slip faulting during the ruptures of the 2002 Denali fault and the 2008 Wenchuan earthquakes. Even though these source models are built using only the teleseismic $P$ waveforms with simple model fault geometry that is represented by a horizontal rectangular plane, they well explain the complex observed waveforms and agree with 
characteristics of source processes obtained in previous studies using seismic and geodetic data as well as field surveys. The potency density tensor inversion method with the time-adaptive smoothing constraint would be a powerful tool to analyze earthquake rupture processes with complex fault geometries involving different faulting styles. 


\section{Introduction}

Large earthquakes are often accompanied by complex fault geometries and slip distributions. Elucidating these complexities is important not only for understanding the source process itself, but also for evaluating the stress field (e.g. Dreger et al., 2004; Nakamura et al., 2010) and future seismicity around the source region (e.g. Hayes et al., 2010; Meng et al., 2012). With the recent development of source process analysis methods, it has been proven that observed body waveforms are sometimes difficult to be explained by the seismic source model using simplified fault plane assumptions (e.g. Shimizu et al., 2020; Yamashita et al., 2021).

It has been challenging to estimate a complex rupture process of an earthquake. There are two major methods to analyze the seismic source process using seismic waveforms: finite-fault inversion (FFI) and back-projection (BP). While the FFI methods can obtain the spatiotemporal distribution of slip rates on an assumed fault plane, it has a weakness in that the obtained result varies depending on the assumption of fault model and underground structure (Yagi \& Fukahata 2011, Minson et al. 2013, Duputel et al. 2014, Ragon et al. 2018, Shimizu et al. 2020). While the BP methods can estimate the seismic radiation by stacking the observed waveforms corrected by the travel-time shifts and the polarity of $P$-waves, the results are affected by reflected phases (Yagi et al. 2012, Okuwaki et al. 2015, Lay et al. 2018), and the theoretical resolution is lower than that of waveform inversion (Fukahata et al. 2014), making it difficult in principle to determine whether the signals included in the results are ghosts or not. Both the FFI and the BP methods easily distort the solution when applied to earthquakes with complex fault geometries. In the case of the FFI methods, the discrepancy between the true and assumed fault geometries causes a modelling error that biases the obtained solution (Ragon et al. 2018, Shimizu et al. 2020) and can lead to incorrect estimation of the rupture propagation direction (Shimizu et al. 2020). In the case of the BP methods, the variation of the fault geometry sometimes leads to temporal changes of the polarity flips, making it difficult to 
obtain coherent signals. There is an urgent need to develop an analysis tool that can provide robust source processes even for earthquakes with complex fault geometries.

Recently, a novel FFI method inverting teleseismic $P$ waveforms has been developed to estimate spatiotemporal rupture evolution with the variation of focal mechanisms, projected onto an assumed model plane (Shimizu et al. 2020). Because this FFI method expresses estimated slip amounts with focal mechanisms as potency density tensors (e.g. Ampuero, 2005) on the assumed model plane, we refer it to a potency density tensor inversion. This inversion method expresses a slip direction on the assumed model plane as a focal mechanism represented by a linear combination of the five basis doublecouple components (Kikuchi \& Kanamori 1991) (Fig. 1), so resulting slip direction is not confined to the assumed strike and dip angles of the model plane. In addition, the Green's function of the teleseismic waveform is insensitive to small deviations in the assumed source location, but sensitive to the assumed fault orientation (Shimizu et al. 2020). Thus, the assumed model plane no longer requires to be compatible with the true fault geometry. This method significantly reduces modelling errors originated from incorrect fault orientations, leading to robust seismic source modelling (Hicks et al. 2020, Okuwaki et al. 2020, Shimizu et al. 2020). Since the Green's function error is explicitly introduced into the data covariance matrix following Yagi \& Fukahata (2011), the slip direction is stably obtained without a non-negative slip constraint (Yagi \& Fukahata 2011, Shimizu et al. 2020), which has been widely used in the conventional FFI methods (e.g. Hartzell \& Heaton 1983, Das \& Kostrov 1990).

The potency density tensor inversion method employs a smoothing constraint as prior information, such that the spatial Laplacian and the second-order time derivative of the potency-rate density function are close to zero (Shimizu et al. 2020). Hyperparameters that control the strength of the smoothing constraint are objectively determined by Akaike's Bayesian Information Criterion from observed data (ABIC; Akaike, 1980; Yabuki \& Matsu'ura, 1992). However, since the same hyper-parameters are used for all the basis double-couple components (Shimizu et al. 2020), relatively 
strong smoothing is imposed on the component with larger amplitude (Yamashita et al. 2021), which makes the inversion solution overly smooth. To mitigate inappropriate strength of the smoothing constraint among the five basis double-couple components, Yamashita et al. (2021) developed formulation that gives a weight of each basis doublecouple component in proportion to its moment tensor solution (e.g. Global Centroid Moment Tensor solution; Dziewonski et al., 1981; Ekström et al., 2012). Although their smoothing constraint has been successfully applied to the 2018 Gulf of Alaska (Yamashita et al. 2021) and 2020 Caribbean (Tadapansawut et al. 2021) earthquakes, it refers to a single moment tensor solution integrated with respect to time and is therefore inflexible for earthquakes where the focal mechanism changes drastically during the rupture, such as the 2002 Denali fault earthquake (Eberhart-Phillips et al. 2003). In addition, their smoothing constraint introduces the constant weight for each basis doublecouple component over the entire source time, although the amplitude of the potency-rate density function of each basis double-couple component is generally time-varying. As a result, when the amplitude was small, relatively weak smoothing is applied, and when the amplitude was large, relatively strong smoothing is applied, resulting in inappropriate smoothness of the solution in the time direction. In order to mitigate this problem, the weights that control the strength of the smoothing need to be time-adaptive as the amplitude changes.

Here, we propose a time-adaptive smoothing constraint that dynamically controls the smoothing hyper-parameters for each basis double-couple component. Following the mathematical reviews of an observation equation for the potency density tensor inversion and formulations of the conventional (Shimizu et al. 2020, Yamashita et al. 2021) and our proposed time-adaptive smoothing constraints, we perform a numerical experiment for a synthetic model with significant changes of the focal mechanism and moment release during rupture, and compare the conventional and time-adaptive smoothing constraints. The numerical experiment shows that although the overall focal mechanism variation of the synthetic model can be obtained with the conventional 
approaches, the time-adaptive smoothing constraint enables us to better reproduce the amplitudes of each basis double-coupled component, which mitigates over- and undersmoothing of slip and fault geometry changes in space and time. We then further evaluate the feasibility and effectiveness of the time-adaptive smoothing constraint on real earthquakes with complex fault rupture. For the applications, we chose the 2002 Denali fault, Alaska and the 2008 Wenchuan, China earthquakes. We finally discuss the advantages and limitations of our new inversion method with the time-adaptive smoothing constraint.

\section{Method}

The potency density tensor inversion method (Shimizu et al. 2020) expresses the slip direction on the assumed model plane $S$ as a superposition of five basis double-couple components (Kikuchi \& Kanamori 1991) (Fig. 1), introducing an error term of the Green's function explicitly (Yagi \& Fukahata, 2011). An observed teleseismic waveform $u_{j}$ at a station $j$ in the potency density tensor inversion can be expressed as

$$
u_{j}(t)=\sum_{q=1}^{5} \int_{S}\left(G_{q j}(t, \xi)+\delta G_{q j}(t, \xi)\right) * \dot{D}_{q}(t, \xi) d \xi+e_{b j}(t)
$$

where $G_{q j}$ is the calculated theoretical Green's function of the $q$-th basis double-couple component, $\delta G_{q j}$ is the model error on $G_{q j}$ (Yagi \& Fukahata 2011), $\dot{D}_{q}$ is the $q$ th potency-rate density function, $e_{b j}$ is a background and instrumental noise, $\xi$ represents a position on $S$, and $*$ denotes the convolution operator in the time domain.

As a prior constraint, Shimizu et al. (2020) adopted the smoothing constraint for the potency-rate density function in space and time, respectively, which can be expressed as

$$
\begin{gathered}
\nabla^{2} \dot{D}_{q}(t, \xi)+e_{s}=0, \\
\frac{\partial^{2}}{\partial t^{2}} \dot{D}_{q}(t, \xi)+e_{t}=0
\end{gathered}
$$

where $e_{s}$ and $e_{t}$ are noises. Eqs (2) and (3) can be rewritten in vector form as follows 


$$
\begin{aligned}
& \boldsymbol{S}_{1} \boldsymbol{a}+\boldsymbol{e}_{s}=0, \\
& \boldsymbol{S}_{2} \boldsymbol{a}+\boldsymbol{e}_{t}=0,
\end{aligned}
$$

where $\boldsymbol{S}_{1}$ and $\boldsymbol{S}_{2}$ are $M \times M$ ( $M$ is the number of model parameters) dimensional matrices, $\boldsymbol{a}$ is the $M$ dimensional model parameter vector, $\boldsymbol{e}_{s}$ and $\boldsymbol{e}_{t}$ are Gaussian noises with mean zero and covariance $\rho_{s}{ }^{2} \mathbf{I}$ and $\rho_{t}{ }^{2} \mathbf{I}$ respectively, and $\mathbf{I}$ is an $M \times M$ ( $M$ is the number of model parameters) unit matrix. Hereinafter, we refer to this smoothing constraint as the unweighted smoothing constraint. Here, $\rho_{s}{ }^{2}$ and $\rho_{t}{ }^{2}$ are unknown scale factors of the variances.

Because Shimizu et al. (2020) assumed the same variances $\left(\rho_{s}{ }^{2}\right.$ and $\left.\rho_{t}{ }^{2}\right)$ for all basis double-couple components and determined their optimal values by ABIC (Akaike 1980, Yabuki \& Matsu'ura 1992, Fukahata et al. 2003, 2004) following Yagi \& Fukahata (2011), strong smoothing is imposed on the portions of the potency-rate density function with relatively large amplitude. Yamashita et al. (2021) focused on over-smoothing for the dominant basis double-couple component and proposed smoothing constraint that replaces the covariances of $\rho_{s}{ }^{2} \mathbf{I}$ and $\rho_{t}{ }^{2} \mathbf{I}$ with $\rho_{s q}{ }^{2} \mathbf{I}$ and $\rho_{t q}{ }^{2} \mathbf{I}$, respectively, weighted in proportion to the ratio of each basis double-couple component to the moment tensor solution, which can be expressed as

$$
\begin{aligned}
& \rho_{s q}{ }^{2} \mathbf{I}=k^{2} w_{q}{ }^{2} \rho_{s}{ }^{2} \mathbf{I}, \\
& \rho_{t q}{ }^{2} \mathbf{I}=k^{2} w_{q}{ }^{2} \rho_{t}{ }^{2} \mathbf{I},
\end{aligned}
$$

where $k$ is a scaling factor and $w_{q}$ is the absolute total potency of the $q$-th basis doublecouple component, which is independently derived from the moment tensor solution. The introduction of extremely small standard deviations imposes strong smoothing on the potency-rate density function, and leads to the amplitude fluctuations in parts where the smoothing is relatively weak, resulting in an unstable solution. To avoid this, the minimum value of $k w_{q}$ was adjusted by an given threshold. In the following, we refer to this smoothing constraint as the moment-tensor-weighted smoothing constraint. 
Although the moment-tensor-weighted smoothing constraint (Yamashita et al. 2021) has been successfully applied to several earthquakes (Tadapansawut et al. 2021, Yamashita et al. 2021), the method only refers to a single moment tensor solution and is therefore inflexible for earthquakes with significant changes in focal mechanism during rupture. In addition, since the value of $w_{q}$ in eqs (6) and (7) is not time-varying over the entire source time, excessively weak smoothing is applied to the part of a potency-rate density function with particularly small amplitude, resulting in an unstable solution. To solve these disadvantages, in this study, we propose a time-adaptive smoothing constraint that time-adaptively changes the values of the standard deviations referring to the potency-rate function for $q$-th component $P_{q}$, which is obtained by integrating the potency-rate density function in space. Then, the covariances $\widehat{\rho}_{s_{q}}(t)^{2} \mathbf{I}$ and $\widehat{\rho}_{t_{q}}(t)^{2} \mathbf{I}$ for the time-adaptive smoothing constraint in space and time, respectively, can be expressed as

$$
\begin{aligned}
& \widehat{\rho_{s}}(t)^{2} \mathbf{I}=\hat{k}^{2} P_{q}(t)^{2} \rho_{s}{ }^{2} \mathbf{I}, \\
& {\widehat{\rho_{t}}}_{q}(t)^{2} \mathbf{I}=\hat{k}^{2} P_{q}(t)^{2} \rho_{t}{ }^{2} \mathbf{I},
\end{aligned}
$$

where $\hat{k}$ is a scaling factor. Since the covariances of the Gaussian noises in eqs (8) and (9) depend on the potency-rate function determined from the model parameters, the inversion problem to be solved becomes non-linear. The potency density tensor inversion framework originally includes a non-linear problem because the data covariance matrix, which introduces the error term of the Green's function, is a function of the model parameters. To solve this non-linear problem, Shimizu et al. (2020) gave initial model parameters to evaluate the data covariance matrix and iteratively solved it by improving the model parameters, following Yagi \& Fukahata (2011). Therefore, in the same way, we can introduce the time-adaptive smoothing constraint with nonlinearity into the potency density tensor inversion framework. We introduce an input potency-rate function $P_{q}^{\text {input }}$ obtained from the initial given model parameters in the first iteration and from the last obtained model parameters in subsequent iterations into eqs (8) and (9). The potencyrate function, obtained by spatially integrating the potency-rate density function, can take 
zero or extremely small values. As explained above, the introduction of such extremely small values for the standard deviations results in an unstable solution. Thus, to prevent the input potency-rate function from having extremely small values, we defined the input potency-rate function $P_{q}^{\text {input }}$ for $n$-th iteration as follows

$$
P_{q}^{\text {input }}(t)^{2}=\max \left(P_{q, n-1}(t)^{2}, c^{2} P_{\max }^{2}\right),
$$

where $P_{q, n-1}$ is the estimated potency-rate function at the $(n-1)$-th iteration, $P_{\max }$ is the maximum value of absolute $P_{q, n-1}$ for all $q$, and $c$ is a lower threshold. Note that in the first iteration $(n=1), P_{q, 0}$ is calculated from the given initial model parameters. The

scaling factor $\hat{k}$ in eqs (8) and (9) is set so that the minimum value of $\hat{k}^{2} P_{q}^{\text {input }}(t)^{2}$ becomes 1. Following Yagi \& Fukahata (2011) and Shimizu et al. (2020), the hyperparameters including $\rho_{s}{ }^{2}$ and $\rho_{t}{ }^{2}$ for each iteration are determined by minimizing $\mathrm{ABIC}$, and the inversion iterations are repeated until the normalized L2 norm between the model parameters of the input and the result becomes acceptably small. We have confirmed that the final solution of the inversion iteration is independent of the setting of the initial model parameters through the following numerical experiment using an input model of next part and applications to real earthquakes shown in the discussion section.

\section{Numerical experiment}

In order to evaluate the performance of the time-adaptive smoothing constraint compared to the unweighted (Shimizu et al. 2020) and moment-tensor-weighted (Yamashita et al. 2021) smoothing constraints, we performed a numerical experiment. We inverted synthetic waveforms obtained from a known input model with each smoothing constraint and compared the obtained results with the input. The input model had three faults with different focal mechanisms: a reverse fault, a right-lateral strike-slip fault and a normal fault (Fig. 2a). The reverse and normal faults are dipping $45^{\circ}$ and the right-lateral strikeslip fault is dipping $90^{\circ}$. Each fault was $80 \times 48 \mathrm{~km}$ in length and width, centered at a depth of $25 \mathrm{~km}$, and was discretized into space knots (sub-fault) of $10 \times 8 \mathrm{~km}$ in length and width. An initial-rupture point was set at a depth of $25 \mathrm{~km}$ on the reverse fault (Fig. 
2a). Slip of each space knot was triggered by a rupture spreading spherically from the hypocenter at $3.3 \mathrm{~km} / \mathrm{s}$ (Fig. S1a). The slip-rate function at each space knot was represented by a combination of bilinear B-spline functions with a time interval of $1.0 \mathrm{~s}$, which had a total duration of $15 \mathrm{~s}$. A total moment tensor calculated by spatiotemporally integrating the potency-rate density tensor distribution showed a pure strike-slip faulting (inset of Fig. 2a) since the dip-slip moment tensor components (M3, M4, M5 components; Fig. 1) related to the input reverse and normal faults canceled each other out. The Green's functions for the input synthetic waveforms were calculated according to the method of Kikuchi \& Kanamori (1991) based on a 1-D velocity structure (Dreger et al. 2004) (Table S1) and were added random Gaussian noise. In addition to the noise of the Green's functions, random Gaussian noises are added to the input synthetic waveforms as the background noise $e_{b j}$. We generated the input synthetic waveforms at the same 45 teleseismic stations (Fig. S2a) as those used in the analysis of the 2002 Denali fault earthquake, which is described later.

Because the potency density tensor inversion method allows for any types of faulting mechanism on the assumed model plane, the inversion can be performed using a horizontal model plane, where the modelling error of fault orientation is replaced by that of fault location, which is less serious in the Green's functions of teleseismic waveforms (Shimizu et al. 2020). Here, we set a horizontal rectangular model plane of $220 \times 60 \mathrm{~km}$ in length and width at a depth of $25 \mathrm{~km}$ covering the input faults (Fig. 2a) and discretized it into space knots of $10 \times 10 \mathrm{~km}$ in length and width. The initial-rupture point was put at the same point as the input. The potency-rate density function at each space knot was represented as a combination of the bilinear B-spline functions with a time interval of 1.0 $\mathrm{s}$, which had a total duration of $15 \mathrm{~s}$. The maximum rupture front velocity, which defines the rupture starting time at each space knot, was set to $3.3 \mathrm{~km} / \mathrm{s}$. We performed inversions with the unweighted, moment-tensor-weighted and time-adaptive smoothing constraints, respectively. 
For the moment-tensor-weighted smoothing constraint, following the numerical experiment of Yamashita et al. (2021), $w_{q}$ in eqs (6) and (7) was calculated by referring to the input total moment tensor with a lower bound of $10 \%$ of $\max \left(w_{q}\right)$. As seen in the paragraph above, since the input total moment tensor is a pure strike-slip faulting (inset of Fig. 2a), the moment-tensor-weighted smoothing constraint imposed relatively large standard deviations on the M1 and M2 components corresponding to the strike-slip components (Fig. 1).

In the time-adaptive smoothing constraint, we set the lower bound $c$ in Eq. (10), and the initial model parameters to obtain the input potency-rate function for the first inversion iteration. We set the lower bound $c$ as 0.2 in the following analyses. Sensitivity of the solution to the value of $c$ was evaluated with $c=0.2 \pm 0.1$, but the selection of $c$ did not affect the solution (Fig. S3). For these tests, we gave a uniform slip model with M1 slip component as the initial model parameters (Fig. S4a). The slip of each space knot is triggered by the presumed rupture front and decays gradually during the rupture duration. Because the time-adaptive smoothing constraint obtains the initial input potency-rate function from the given initial model parameters, the final solution may depend on the initial model parameter settings. To investigate the dependence, we inverted the numerical models with three different initial conditions: a uniform pure strike slip (M1), a uniform reverse slip (M5), and a striped slip (Fig. S4). The obtained results do not show a major difference (Fig. S4), indicating the independence of the final solution to the initial model parameter settings. In the following, we use the uniform M1 slip as an initial model parameter.

Figure 2 shows the potency density tensor distribution obtained by the three types of smoothing constraints. Figure 3 shows the input and resultant moment rate functions of the M1, M2 and M5 slip components included in the input model, obtained by spatially integrating the potency-rate density function multiplied by the rigidity. Although the model geometries are different between the input fault and the model fault and the quantitative measure of model discrepancy may not be rigorously made in that 
context, the comparison of the total seismic moment can be useful indexes of discrepancy from the input.

In the unweighted smoothing constraint (Fig. 2b), the obtained spatial focal mechanism distribution well captures the input fault geometry. On the other hand, the obtained total seismic moment was underestimated by $15 \%$ of the input. The moment rate function for each basis double-couple component shows that the M1 and M2 strike-slip components (Fig. 1) are significantly underestimated compared to the input from 20 to $40 \mathrm{~s}$ (Figs. 3a and $\mathrm{b}$ ). These results show that the unweighted smoothing constraint certainly impose too strong smoothing for the components with large amplitude, which results in underestimated solution.

The moment-tensor-weighted smoothing constraint well reproduced the moment rate function of the M1 and M2 strike-slip components from 20 to $40 \mathrm{~s}$ (Figs. 3a and b) because they introduced relatively large variances for these components referring to the input total moment tensor (inset of Fig. 2a). The obtained total seismic moment overestimates the input by $7 \%$, and this deviation is smaller than that of the unweighted smoothing constraint. However, the moment rate function of the M5 dip-slip component underestimates the amplitude around 10 and $50 \mathrm{~s}$, where the dip-slip should be dominant (Fig. 3c), indicating that the moment-tensor-weighted smoothing constraint cannot adequately estimates the time evolution of the focal mechanism, which differs significantly from the referenced moment tensor solution. In addition, the moment-tensorweighted smoothing constraint consistently weakens the smoothing of the M1 and M2 strike-slip components, allowing perturbation of these components even when the observed signals related to M1 and M2 are small (enlarged views in Figs. 3a and b), leading to instability of the focal mechanism distribution in the northwestern and southeastern parts of the model plane (Figs. 2c and S1c).

In the time-adaptive smoothing constraint, the perturbation of the M1 and M2 strike-slip components are suppressed around 10 and $50 \mathrm{~s}$ when their amplitudes are minor, and are properly resolved from 20 to $40 \mathrm{~s}$ when these components are dominant 
along the strike-slip fault section (Figs. 3a and b). This result suggests the importance of controlling the smoothing hyper-parameters not only among basis double-couple components but also in the time direction. The obtained focal mechanism distribution clearly captures the geometrical changes of the three input fault planes (Figs. 2d and S1d), including the reverse and normal faults, which are destabilised under the moment-tensorweighted smoothing constraint (Figs. $2 \mathrm{c}$ and S1c). This result demonstrates the ability of the time-adaptive smoothing constraint to properly estimate abrupt changes in fault geometry. Although the obtained total seismic moment still underestimates the input by $6 \%$ due to the noise arbitrarily added in generating the synthetic waveforms and the modelling errors, this deviation is smaller than that of the unweighted smoothing constraint, indicating that the time-adaptive smoothing constraint mitigates the underestimation due to over-smoothing. The absolute deviation of the total seismic moment from the input is almost the same between the moment-tensor-weighted and time-adaptive smoothing constraints, but the moment rate functions of the M1 and M2 strike-slip components show that the time-adaptive smoothing constraint outperforms the moment-tensor-weighted smoothing constraint in terms of stability (Figs. 3a and b). In summary, the time-adaptive smoothing constraint enables us to estimate the details of complex fault ruptures that are difficult to reproduce with the conventional smoothing constraints by controlling the hyper-parameters with the input potency-rate function for each basis double-couple component.

\section{Applications to real earthquakes}

This section examines the feasibility and effectiveness of the time-adaptive smoothing constraint for real earthquakes. For the purpose, we selected two earthquakes: the 2002 Denali fault, Alaska and the 2008 Wenchuan, China earthquakes. The fault geometries of these earthquakes have been well constrained by aftershock distributions, geodetic data, and field surveys in previous studies and the change of focal mechanism from reverse to strike-slip has been identified (see details in the later subsections). 
For the analyses, the teleseismic $P$ waveform data (vertical components) were downloaded from the Incorporated Research Institutions for Seismology Data Management Center (IRIS-DMC). The stations used in our analyses were located at epicentral distance of $30-90^{\circ}$ and were selected to ensure a high-signal-to-noise ratio and an azimuth coverage. We used 45 and 46 stations for the analyses of the 2002 Denali fault and the 2008 Wenchuan earthquakes, respectively (Figs. S5a and S6a). The instrumental responses of the data were removed and converted to velocity waveforms at a sampling rate of $0.8 \mathrm{~s}$. The theoretical Green's functions were calculated by the method of Kikuchi $\&$ Kanamori (1991) at a sampling rate of $0.1 \mathrm{~s}$, and the attenuation time constraint $t^{*}$ for the $P$ wave was taken to be $1.0 \mathrm{~s}$. We employed the $1-\mathrm{D}$ velocity structure model used by Dreger et al. (2004) (Table S1) for the 2002 Denali fault earthquake, and the CRUST 1.0 model (Laske et al. 2013) (Table S2) for the 2008 Wenchuan earthquake. Following Yamashita et al. (2021), we did not apply a low-pass filter to the observed waveforms or calculated Green's functions. To reduce arbitrariness of the assumption about the fault geometry, we assumed a horizontal model plane covering the rupture area. According to the numerical experiment procedure, we set the lower bound $c=0.2$ and continued the loop until the solution converged (Yagi \& Fukahata 2011) for the time-adaptive smoothing constraint.

The November 3, 2002 Denali fault earthquake

The 2002 Denali fault earthquake ruptured three faults with thrust and strike-slip faulting from west to east: the Susitna Glacier, Denali and Totschunda (Eberhart-Phillips et al. 2003, Haeussler et al. 2004) (Fig. 4). Surface rupture of the Susitna Glacier fault shows overall thrust fault motion (Eberhart-Phillips et al. 2003, Crone et al. 2004, Haeussler et al. 2004). The Denali and Totschunda faults are dominated by right-lateral strike-slip faulting, including vertical displacement (Eberhart-Phillips et al. 2003, Haeussler et al. 2004). Surface rupture of theses faults extended $341 \mathrm{~km}$ (Haeussler et al. 2004) and the maximum measured horizontal offset was $8.8 \mathrm{~m}$ about $190 \mathrm{~km}$ east of the epicenter (Eberhart-Phillips et al. 2003). The hypocenter determined by the U.S. Geological Survey, 
National Earthquake Information Center (USGS NEIC) is located at $63.514^{\circ} \mathrm{N}$, $147.453^{\circ} \mathrm{W}$ and a depth of $4.2 \mathrm{~km}$ (Fig. 4). The Global Centroid Moment Tensor (GCMT) solution (Dziewonski et al. 1981, Ekström et al. 2012) is located about $130 \mathrm{~km}$ east of the epicenter and shows a predominantly strike-slip faulting (Fig. 4). Aftershock seismicity ( $M \geq 3.5,3-9$ November 2002) (U.S. Geological Survey Earthquake Hazards Program 2017) is concentrated around the ruptured three faults (Fig. 4).

Given the distributions of surface rupture traces (Koehler et al. 2012) and aftershocks (U.S. Geological Survey Earthquake Hazards Program 2017) (Fig. 4), we set up a horizontal model plane of $336 \times 96 \mathrm{~km}$ in length and width with a strike of $296^{\circ}$, which is the same as the strike angle of the north-dipping nodal plane of the GCMT solution (Dziewonski et al. 1981, Ekström et al. 2012). We adopted the epicentral location determined by the USGS NEIC for the initial-rupture point at $63.514^{\circ} \mathrm{N}$ and $147.453^{\circ} \mathrm{W}$ (Fig. 4). Since the aftershock distribution is concentrated in shallow depth of $10 \mathrm{~km}$, suggesting that the rupture has not reached deep underground (Eberhart-Phillips et al. 2003), we placed the model plane at a depth of $5 \mathrm{~km}$. The potency-rate density function along the model plane was expanded using a bilinear B-spline with a spatial interval of $12 \mathrm{~km}$ and a temporal interval of $0.8 \mathrm{~s}$ with a total duration of $44 \mathrm{~s}$. The potency-rate density function was estimated up to $100 \mathrm{~s}$ from the origin time (e.g. Ji et al. 2004, Asano 2005). The maximum rupture front velocity was set to $5 \mathrm{~km} / \mathrm{s}$ to account for the possibility of supershear rupture propagation (Dunham \& Archuleta 2004, Ellsworth et al. 2004, Frankel 2004, Asano 2005, Walker \& Shearer 2009).

The obtained moment rate function has peaks at 9.6, 32.0 and 59.2 s (Fig. 5a), with the total seismic moment of $1.42 \times 10^{21} \mathrm{Nm}\left(M_{\mathrm{W}} 8.04\right)$. The moment rate function of each basis double-couple component shows that the first peak is dominated by the M5 dip-slip component, and the last two peaks are dominated by both the M1 and M2 strikeslip components (Fig. 5b). The time evolution of the potency-rate density along the strike direction shows that the three peaks of the moment rate function correspond to large potency-rate density patches near the epicenter, around the intersection of the Denali fault 
and the Trans-Alaska Pipeline System (TAPS), and just before the junction between the Denali and Totschunda faults, respectively (Fig. 5c). These spatial distributions are consistent with the estimated location of the three sub-events identified in the strong motion studies (Eberhart-Phillips et al. 2003, Frankel 2004). The snapshot shows that the rupture initiated around the Susitna Glacier fault (Fig. 5d). The moment tensor solution obtained by integrating the potency-rate density tensors in time and space for each time window are shown in the inset of Fig. $5 \mathrm{~d}$. The initial rupture was dominated by reverse faulting and lasted until about $20 \mathrm{~s}$ from the origin time (Fig. 5d). Then, the rupture propagates unilaterally from west to east along the Denali-Totschunda fault with predominantly strike-slip faulting (Fig. 5d). The strike direction of the nodal plane derived from each moment tensor matches the orientation of the Denali-Totschunda fault from 20 to $80 \mathrm{~s}$ with a gradual rotation of $16^{\circ}$ clockwise from $280^{\circ}$ to $116^{\circ}$ (Fig. $5 \mathrm{~d}$ ), which is consistent with the negative peak of the M2 component lagging behind the positive peak of the M1 component in the moment rate function (Fig. 5b). The synthesized waveforms obtained our source model explain the observed waveforms well (Figs. 5e and $\mathrm{S} 5 \mathrm{~b})$.

The centroid migration velocity of the potency-rate density decelerates around the Denali fault-TAPS intersection but accelerates before and after it (Fig. 5c). The estimated average centroid location migration speeds are $3.16 \mathrm{~km} / \mathrm{s}$ for $10-40 \mathrm{~s}$, where the centroid is located west of the TAPS. Then, the migration velocity decelerates to 2.47 $\mathrm{km} / \mathrm{s}$ during $30-50 \mathrm{~s}$ when the centroidal location passes through the TAPS, but accelerates to $4.64 \mathrm{~km} / \mathrm{s}$ for $40-70 \mathrm{~s}$, where the centroid is located east of the TAPS (Fig. 6). The latter exceeds the local $S$-wave velocity of $3.35 \mathrm{~km} / \mathrm{s}$ at a depth of $5 \mathrm{~km}$ where the model plane is set (Table S1). Several studies have proposed that the rupture partially propagated at a supershear speed on the Denali fault, but the estimated velocities varied (Dunham \& Archuleta 2004, Ellsworth et al. 2004, Frankel 2004, Asano 2005, Walker \& Shearer 2009). Although we cannot directly compare our estimated centroid migration speed with rupture front velocities estimated in other studies (Shimizu et al. 2020), the 
feature of faster rupture propagation on the eastern ruptured section of the Denali fault is consistent with that resolved by the BP method using teleseismic $P$-waves (Walker \& Shearer 2009).

The focal mechanism projected onto the assumed model plane represents a reverse faulting with a nearly E-W strike direction near the Susitna Glacier fault and a strike-slip faulting with a clockwise rotation of the strike direction from west to east on the Denali-Totschunda fault (Fig. 5d). These results are consistent with surface ruptures observed by field surveys (Eberhart-Phillips et al. 2003, Haeussler et al. 2004) and finitefault models constructed using multiple fault planes (Dreger et al. 2004, Ji et al. 2004, Asano 2005). After $70 \mathrm{~s}$ from the origin time, when the rupture propagates from the Denali fault to the Totschunda fault, the dip-slip components become larger in addition to the strike-slip components (Figs. 5b and d). Field surveys have reported that the transfer zone of the Denali and Totschunda faults has a series of the right-stepping fault segments connected by north-striking normal faults (Eberhart-Phillips et al. 2003, Haeussler et al. 2004), suggesting that the preponderance of dip-slip components in our source model may reflect such geometric complexity of the transfer zone.

The May 12, 2008 Wenchuan earthquake

The 2008 Wenchuan earthquake occurred in the Longmenshan Thrust Belt, which lies between the Tibetan Plateau and the Sichuan Basin (Fig. 7). Field studies show that the earthquake ruptured primarily three faults: the Beichuan, Pengguan and Xiaoyudong (Liu-Zeng et al. 2009, Xu et al. 2009) (Fig. 7). The surface rupture of the Beichuan fault extends over 200-km-long in a NE-SW direction with right-lateral reverse displacements (Liu-Zeng et al. 2009, Xu et al. 2009). The Pengguan fault extends about $72 \mathrm{~km} \mathrm{sub-}$ parallel to the southern trace of the Beichuan fault about $12 \mathrm{~km}$ east, and a reverse component is dominant ( $\mathrm{Xu}$ et al. 2009). The Beichuan fault and the southern end of the Pengguan fault are connected by the NW-striking Xiaoyudong fault, which has left-lateral strike-slip displacements (Liu-Zeng et al. 2009, Xu et al. 2009). The hypocenter 
determined by the USGS NEIC is located at $31.002^{\circ} \mathrm{N}, 103.322^{\circ} \mathrm{E}$ and a depth of 19.0 km. The GCMT solution (Dziewonski et al. 1981, Ekström et al. 2012) is located about $89 \mathrm{~km}$ northeast of the epicenter and shows an oblique thrust faulting (Fig. 7). Aftershocks ( $M \geq 3.5$, 12-18 May 2008) (U.S. Geological Survey Earthquake Hazards Program 2017) are distributed along the surface rupture traces (Fig. 7).

Based on the distributions of observed surface rupture (Xu et al. 2009) and aftershocks (U.S. Geological Survey Earthquake Hazards Program 2017), we designed a horizontal model plane of $341.0 \times 59.5 \mathrm{~km}$ in length and width with a strike of $225^{\circ}$ (Fig. 7). We put the horizontal model plane at a depth of $12.8 \mathrm{~km}$ according to the centroid depth of the GCMT solution (Dziewonski et al. 1981, Ekström et al. 2012) (Fig. 7). This depth falls within the 10-19 km depth range reported in previous studies (e.g. Fielding et al., 2013; U.S. Geological Survey Earthquake Hazards Program, 2017). We expanded the potency-rate density function along the model plane into bilinear B-splines with a spatial interval of $11.0 \times 8.5 \mathrm{~km}$ in length and width, and a temporal interval of $0.8 \mathrm{~s}$ with a total duration of $60 \mathrm{~s}$. The potency-rate density function was estimated up to $130 \mathrm{~s}$ from the origin time (Yagi et al., 2012). For the initial-rupture point, we adopted the epicenter determined by the USGS NEIC at $31.002^{\circ} \mathrm{N}$ and $103.322^{\circ} \mathrm{E}$. The maximum rupture front velocity was set at $3.53 \mathrm{~km} / \mathrm{s}$ corresponding to the local $S$-wave velocity (Table S2).

In Fig. 8, we show the inversion results with the time-adaptive smoothing constraint. The moment rate function represents a major peak at $26.4 \mathrm{~s}$ (Fig. 8a), with the total seismic moment of $1.82 \times 10^{21} \mathrm{Nm}\left(M_{\mathrm{W}} 8.11\right)$. The moment rate function for each basis double-couple component shows that the M3 and M5 dip-slip components and the M1 and M2 strike-slip components are dominant around the peak (Fig. 8b). The time evolution of the potency-rate density along the strike direction (Fig. 8c) shows a large value for 20-40 s, corresponding to the peak of the moment rate function (Fig. 8a). This large slip can be divided into two parts: the vicinity of the rupture front and an area centered about $30 \mathrm{~km}$ northeast from the epicenter (Fig. 8c). The rupture front part moves to the northeast as the rupture area expands, but the other part stagnates just before the 
Xiaoyudong fault (Figs. 8c and d). The snapshot shows that the rupture roughly propagated unilaterally from the epicenter to the northeast, in which reverse faulting was predominant until $60 \mathrm{~s}$ from the origin time (Fig. 8d). For 50-60 s, the knot that records the maximum potency-rate density reached about $110 \mathrm{~km}$ northeast of the epicenter. However, for 60-70 s, the location of the maximum knot receded to about $77 \mathrm{~km}$ northeast of the epicenter and the moment tensor thereafter turned into strike-slip faulting (Fig. 8d). The rupture then propagates unilaterally to the northeast direction until the end (Fig. 8d). The synthesized and observed waveforms are well fitted (Figs. 8e and S6b).

The moment tensor shows predominantly thrust faulting until $60 \mathrm{~s}$ from the origin time and then transitions to oblique strike-slip faulting (Fig. 8d). This rake angle rotation toward the northeast from the epicenter is consistent with those estimated by other finite-fault models (Shen et al. 2009, Feng et al. 2010, Nakamura et al. 2010, Yagi et al. 2012, Fielding et al. 2013, Hartzell et al. 2013). The main rupture, which was propagating northeastward until $20 \mathrm{~s}$, was stagnated in front of the Xiaoyudong fault connecting the Beichuan and Pengguan faults between 20 and 40 s (Fig. 8d), which can be interpreted as the Xiaoyudong fault acting as a geometric barrier preventing the rupture evolution. The timing of the main rupture stagnation is close to the high-frequency emission for 15-25 s near the Xiaoyudong fault detected by the hybrid BP (HBP) method (Okuwaki \& Yagi, 2018), which estimates the spatiotemporal distribution of the seismic radiation sources on the assumed fault model by stacking the cross-correlation functions of the observed waveforms and the corresponding Green's functions (Yagi et al., 2012). These results are consistent with numerical models and observations that high frequencies are generated when the rupture front velocity changes abruptly (e.g. Madariaga, 1977; Okuwaki et al., 2015).

Yagi et al. (2012) applied a developed FFI method (Yagi \& Fukahata 2011), which introduced the uncertainty of the Green's function and was a prototype of the potency density tensor inversion method, to the 2008 Wenchuan earthquake. Their sliprate evolution generally agrees with our result, even though their FFI method allows only 
the two basis double-couple components compatible to the assumed fault plane. This suggests that the low degrees of freedom of the conventional source model may be mostly adequate when the discrepancy between the true and assumed fault geometries is sufficiently small. However, if we look at the details of the inverted results, for example, our source model identified the high-potency-rate density area near the rupture front between 20 and $40 \mathrm{~s}$, in addition to the stagnated rupture in front of the Xiaoyudong fault (Fig. 8d). This high-potency-rate density area has significant strike-slip components and thus is distinct from the stagnated rupture with mainly reverse faulting (Fig. S7). On the other hand, Yagi et al. (2012) did not identify the significant strike-slip near the rupture front from 20 to $40 \mathrm{~s}$. This suggests that the FFI method is insufficient to estimate a rupture process when the focal mechanism varies. Such a complex rupture process may have been obscured in the conventional FFI methods due to modelling errors caused by the confinement of slip direction and an inappropriate assumption of fault geometry. In contrast, the potency density tensor inversion with high degrees of freedom can successfully estimate the variation of focal mechanisms as well as the complex rupture behavior, which has not been unveiled by the conventional FFI method.

\section{Discussion}

Merits of the time-adaptive smoothing constraint

The numerical experiment highlighted the over-smoothing problem of the unweighted smoothing constraint (Shimizu et al. 2020). The unweighted smoothing constraint imposed excessively strong smoothing on the portions of the potency-rate density function with relatively large amplitudes, leading to an underestimation of moment release. Such excessive smoothing to the dominant basis double-couple component can be mitigated by the moment-tensor-weighted smoothing constraint (Yamashita et al. 2021), but the numerical experiment involving focal mechanism variations for reverse, right-lateral strike-slip and normal faults showed that this smoothing constraint only works well when the focal mechanisms during the rupture process are not significantly 
different from the referenced moment tensor solution. The numerical experiment also showed that because the moment-tensor-weighted smoothing constraint imposed constant values of the hyper-parameters over entire source time, a basis double-couple component with a large amplitude is subject to relatively weaker smoothing even in the portions of a small amplitude, which destabilizes the solution (Figs. 3a and b). The time-adaptive smoothing constraint overcomes these weaknesses of the previously used smoothing constraints by controlling the values of the hyper-parameters not only among basis double-couple components but also in the time direction, and thus it reproduced well the complex input source model.

In the application to the 2002 Denali fault earthquake, the inversion result with the time-adaptive smoothing constraint showed that the rupture exhibited thrust faulting until about $20 \mathrm{~s}$ from the origin time, then changed to strike-slip faulting and propagated from west to east, with its strike rotating clockwise between 20 and $80 \mathrm{~s}$. These changes of the focal mechanism are consistent with the surface rupture of the Susitna Glacier fault and the Denali-Totschunda fault, respectively, obtained from field studies (EberhartPhillips et al. 2003, Crone et al. 2004, Haeussler et al. 2004). The application to the 2008 Wenchuan earthquake showed that the rupture propagated mainly unilaterally from the epicenter to the northeast, and the obtained focal mechanism changed from thrust to oblique strike-slip faulting, which is consistent with the finite-fault model of previous studies (Shen et al. 2009, Feng et al. 2010, Nakamura et al. 2010, Yagi et al. 2012, Fielding et al. 2013, Hartzell et al. 2013). Our result clearly distinguished the frontal rupture of strike-slip faulting and the stagnated rupture of reverse faulting near the Xiaoyudong fault from 20 to $40 \mathrm{~s}$, but such a complex rupture process has been difficult to be reproduced with conventional finite-fault models in which the slip vector is fixed to the assumed fault plane. In both applications to real earthquakes, the time-adaptive smoothing constraint successfully estimated complex rupture propagation processes, including fault geometry changes. 
To further evaluate the effectiveness of the time-adaptive smoothing constraint in the real earthquakes, we performed the potency density tensor inversion with the conventional smoothing constraints (Shimizu et al. 2020, Yamashita et al. 2021) for the 2002 Denali fault earthquake. We then compared these results to those obtained with the time-adaptive smoothing constraint. For these analyses, the parameter settings other than the smoothing constraint were the same as the case with the time-adaptive smoothing constraint. For the moment-tensor-weighted smoothing constraint, $w_{q}$ in eqs (6) and (7) was calculated by referring to the GCMT solution (Dziewonski et al. 1981, Ekström et al. 2012) of the 2002 Denali fault earthquake with a lower bound of $10 \%$ of $\max \left(w_{q}\right)$ following Yamashita et al. (2021).

The moment rate functions of the five basis double-couple components obtained with the unweighted smoothing constraint are in rough agreement with those obtained with the time-adaptive smoothing constraint (Fig. 9a). The time development of the potency-rate density and the centroid location of the unweighted smoothing constraint are also approximately consistent with those of the time-adaptive smoothing constraint (Figs. $5 \mathrm{c}$ and $9 \mathrm{~b}$ ). However, the moment rate function of the M1 strike-slip component obtained with the unweighted smoothing constraint underestimate the peak amplitude around $30 \mathrm{~s}$, obscuring the high-potency-rate density area around the Denali fault and TAPS intersection (Figs. 5c and 9b). The presence of this high-potency-rate density area is supported by the location of the sub-event identified from the strong motion data (Eberhart-Phillips et al. 2003, Frankel 2004) and the increase in surface offset from the field survey (Eberhart-Phillips et al. 2003). These results reflect that the unweighted smoothing constraint over-smooths the source signal with particularly large amplitude, as exemplified in the numerical experiment. As a result, the features of the potency-rate density distribution become blurred (Fig. 9b), making the interpretation of the rupture propagation difficult.

The moment-tensor-weighted smoothing constraint weakens the smoothness to the M1 and M2 strike-slip components (Fig. 1) referring to the GCMT solution (Fig. 4). 
We show snapshots up to $20 \mathrm{~s}$ from the origin time (Figs. 10a and b), when the dip-slip component is dominant (Fig. 5b) unlike the GCMT solution. The snapshot obtained with the moment-tensor-weighted smoothing constraint shows that high-potency-rate density patches are scattered from 5 to $20 \mathrm{~s}$ (Fig. 10a) and the strike direction of the moment tensor rotates nearly $90^{\circ}$ from $0-5 \mathrm{~s}$ to $5-10 \mathrm{~s}$ (inset of Fig. 10a). A high-potency-rate density patch distributed in the southeastern region of the epicenter from 10 to 20 s shows unrealistic focal mechanisms that are sign-flipped from the referenced GCMT solution (Fig. 10a). On the other hand, the snapshot obtained with the time-adaptive smoothing constraint shows a stable potency-rate density distribution while capturing the realistic variation of the focal mechanisms and moment tensor (Fig. 10b). These results show that the moment-tensor-weighted smoothing constraint destabilizes the solution by inappropriate weighting of smoothness constraint when the referenced moment tensor and the focal mechanism for a particular time period deviate significantly, as also shown in the numerical experiment. The moment-tensor-weighted smoothing constraint imposes the same weight over entire source time without distinguishing the slip direction for each basis double-couple component. Therefore, even when the source signal is too small to constrain the focal mechanism, the smoothing can be excessively weak, leading to unrealistic focal mechanisms that are sign-flipped from the referenced moment tensor solution. Such artificial focal mechanism possibly may occur even with the time-adaptive smoothing because the potency density tensor inversion method does not apply the nonnegative slip constraint and the time-adaptive smoothing constraint also weights the five basis double-couple components without distinguishing the slip direction. Nonetheless, since the time-adaptive smoothing constraint controls the hyper-parameters not only in each basis double-couple component but also in the time direction referring to the potency-rate function, it successfully estimates reasonable focal mechanisms even at 10 $20 \mathrm{~s}$ (Fig. 10b), when the amplitude of the potency-rate function is relatively small (Fig. $5 b)$. 
How do we better assign the model planar geometry?

Through the numerical experiment and application to the real earthquakes, we show that the potency density tensor inversion method with the time-adaptive smoothing constraint can be used to project complex rupture propagation onto a horizontal model plane. The potency density tensor inversion method no longer requires an assumption of a rigorous fault geometry, which is a distinct advantage in comparison with the conventional FFI methods; the method provides a robust source model as in the BP method, which also assumes only a horizontal model region to detect a source process. The horizontal model plane, however, cannot properly represent the depth variation of the Green's function because all source knots are located at the same depth (Shimizu et al. 2020). The Green's function of the teleseismic $P$ waveform includes not only the direct phase, but also depth phases reflected at the ground surface near the epicenter, which contain information about the depth of the source. The assumption of a horizontal model plane ignores such source depth information included in the teleseismic waveforms and undermines the high depth resolution, which can be detected by the FFI method using teleseismic waveforms (Yagi 2004, Hartzell et al. 2013). If realistic fault geometry of an earthquake can be approximated by a single model plane, the assumption of an inclined model plane may provide a detailed rupture process including depth resolution. Here, to investigate the effect of the depth variation of the Green's function on the potency density tensor inversion method with the time-adaptive smoothing constraint, we reanalyzed the 2008 Wenchuan earthquake, whose fault geometry is relatively easy to approximate by a single inclined plane, and compared the result with that obtained for a horizontal model plane.

Although finite-fault models with multiple fault planes have been constructed for the 2008 Wenchuan earthquake based on geodetic and geological data (e.g. Shen et al. 2009, Fielding et al. 2013, Hartzell et al. 2013), here we employ a single model plane to simply investigate the effect of depth variation on the Green's function. The assumed model plane has a dip of $32^{\circ}$ and an epicentral depth of $16 \mathrm{~km}$, referring to Yagi et al. (2012), while fixing the strike to $225^{\circ}$ used in the horizontal model plane analysis. The 
spatial knots of the model plane were reduced from 8.5 to $7.5 \mathrm{~km}$ in the depth direction so that the model plane does not extend beyond the ground surface. Because the rupture reached the ground surface (Liu-Zeng et al. 2009, Xu et al. 2009), we did not impose a constraint to make the potency-rate density zero at the top of the model plane. The model settings other than those described above are the same as in the analysis of the horizontal model plane.

In the result of the inclined plane model, the rupture initiating at the hypocenter propagates to the northeast (Fig. 11). The main rupture is arrested in the vicinity of the Xiaoyudong fault zone at about $20 \mathrm{~s}$ from the origin time and comes back to the epicenter until about $50 \mathrm{~s}$ (Fig. 11). Meanwhile, the near-surface rupture that appears after $20 \mathrm{~s}$ continues to propagate northeastward until $60 \mathrm{~s}$ as the rupture front expands (Fig. 11). At 60-70 s, a high-potency-rate density area suddenly appears in the center of the Pengguan fault zone and propagates to the northeast until the end (Fig. 11).

The rupture process obtained on the inclined model plane generally agrees with that obtained on the horizontal model plane, suggesting the effect of the depth variation of the Green's function is insignificant, which is consistent with previous studies using the potency density tensor inversion method with the unweighted or the moment-tensorweighted smoothing constraints (Shimizu et al. 2020, Yamashita et al. 2021). On the other hand, the inclined plane model has the advantage of providing a detailed rupture behavior in the depth direction that is not visible in the horizontal plane model. For example, the rupture extension near the Xiaoyudong fault zone beneath the near-surface rupture around the rupture front at 20-30 s was not clearly captured by the horizontal plane model (Figs. 8d and 11).

We also found minor differences in the rupture behavior not only in the depth direction but also in the strike direction between the horizontal and inclined plane models. Among them, the most conspicuous difference is the rupture behavior after the stagnation near the Xiaoyudong fault at 20-30 s (Figs. 8d and 11). In the horizontal plane model, the rupture was arrested just before the Xiaoyudong fault until $40 \mathrm{~s}$ (Fig. 8d). On the other 
hand, in the inclined plane model, the rupture that stagnated at about $20 \mathrm{~s}$ started to propagate toward the hypocenter until $50 \mathrm{~s}$ (Fig. 11). The joint inversion using geodetic, teleseismic and strong motion data estimated bilateral ruptures toward the northeast and southwest directions on the Beichuan fault (Hartzell et al., 2013). The HBP method also showed that high-frequency sources stagnated near the Xiaoyudong fault for 15-25 s and then propagated bilaterally to the northeast and southwest (Okuwaki \& Yagi, 2018). These results support that the back rupture propagation obtained for the inclined plane model is not an artifact. Introduction of the depth variation to the model plane enables us to capture the back rupture propagation.

The success of the inclined plane model shows the importance of including the depth variation to the assumed source knot, which enhances the possibility of capturing a more detailed source process. However, since putting a inclined model plane requires prior information about the fault geometry, it is difficult to apply the model to earthquakes where the fault geometry is poorly constrained due to the lack of surface rupture, such as the 2010 Haiti earthquake (Hayes et al. 2010, Prentice et al. 2010, Hashimoto et al. 2011). In addition, a single inclined model plane is difficult to approximate for a fault system with complex geometry, such as the 2002 Denali fault earthquake. Compared to the inclined model plane, the horizontal model plane requires little information about the fault geometry and is widely applicable (Shimizu et al. 2020).

Initial model dependence of the time-adaptive smoothing constraint

The time adaptive smoothing constraint is designed so that the relative smoothing becomes weaker in the time period with large amplitude referring to the input potencyrate function, which may lead to an initial model dependence. However, the final solution remained stable even when an unrealistic initial model was used as an input model (Fig. S4). To examine the effect of the initial selection of an input potency-rate function on the results of the real earthquakes, we tested two types of initial models: uniform slips of the M1 and M5 slip components (Fig. 1), respectively. Comparing the results for both 
earthquakes, we find no significant difference in the final solution obtained using either of the initial models (Fig. S8). This result shows that the final solution is independent of the initial model parameter settings in the potency density tensor inversion method with the time-adaptive smoothing constraint. Such robustness of the solution suggests that the potency-rate function is stably obtained from the teleseismic body waves that can be approximated by the convolution function of the potency-rate function and the Green's function of centroid.

\section{Conclusion}

We developed a potency-density tensor approach of the teleseismic finite-fault inversion, by using the time-adaptive smoothing constraint that dynamically adjusts the smoothing intensity referring to the potency-rate functions of the basis double couple components, which is designed to mitigate the excessive smoothing on the portions with relatively large amplitude of the potency-rate density function. We tested feasibility of our developed approach through both the numerical experiments and the applications to the real earthquakes; the 2002 Denali fault and the 2008 Wenchuan earthquakes. We found that our approach successfully resolved complex source processes involving the localized distribution of multiple high-potency-rate density areas and the transition from reverse to strike-slip in the focal mechanism during rupture along a horizontal rectangular model plane covering the potential rupture area. In other words, our approach can estimate the spatiotemporal rupture evolution of a complex fault system, including information on fault geometry, from only teleseismic $P$ waveforms. Our study highlights that the potency density tensor inversion method with the time-adaptive smoothing constraint is a powerful waveform analysis tool for earthquakes with complex fault rupture.

\section{Acknowledgements}

We thank the editor and the reviewers for evaluating the manuscript. This work was supported by the Grant-in-Aid for Scientific Research (C) 19K04030. The facilities of IRIS Data Services, and specifically the IRIS Data Management Center, were used for 
access to waveforms, related metadata, and/or derived products used in this study. IRIS Data Services are funded through the Seismological Facilities for the Advancement of Geoscience (SAGE) Award of the National Science Foundation under Cooperative Support Agreement EAR-1851048. All the figures were generated with matplotlib (v3.1.1: $\quad$ https://doi.org/10.5281/zenodo.3264781), $\quad$ ObsPy $\quad$ (v1.1.0: https://doi.org/10.5281/zenodo.165135) and Generic Mapping Tools (v5.4.5).

\section{Data availability}

Waveform data was downloaded through the IRIS Wilber 3 system (https://ds.iris.edu/wilber3/find_event). Teleseismic waveforms were obtained from the following networks: Berkeley Digital Seismograph Network (BK; https://doi.org/10.7932/BDSN); the Canadian National Seismograph Network (CN; https://doi.org/10.7914/SN/CN); the Czech Regional Seismic Network (CZ; https://doi.org/10.7914/SN/CZ); the GEOSCOPE (G; https://doi.org/10.18715/GEOSCOPE.G); the GEOFON (GE; https://doi.org/10.14470/TR560404); the New China Digital Seismograph Net- work (IC; https://doi.org/10.7914/SN/IC); the IRIS/IDA Seismic Network (II; https://doi.org/10.7914/SN/II); the IRIS/USGS Global Seismograph Network (IU; https://doi.org/10.7914/SN/IU); the Mediterranean Very Broadband Seismographic Network (MN; https://doi.org/10.13127/SD/fBBBtDtd6q); the Pacific21 (PS; https://www.fdsn.org/networks/detail/PS/). The moment tensor solutions are obtained from the GCMT catalog (https://www.globalcmt.org/CMTsearch.html). The CRUST 1.0 model is available at https://igppweb.ucsd.edu/ gabi/crust1.html.

\section{References}

Akaike, H. (1980) Likelihood and the Bayes procedure. Trab. Estad. Y Investig. Oper., 31, 143-166, Springer-Verlag. doi:10.1007/BF02888350 
Ampuero, J.-P. (2005) Ambiguity of the Moment Tensor. Bull. Seismol. Soc. Am., 95, 390-400. doi:10.1785/0120040103

Asano, K. (2005) Estimation of Source Rupture Process and Strong Ground Motion Simulation of the 2002 Denali, Alaska, Earthquake. Bull. Seismol. Soc. Am., 95, 1701-1715. doi:10.1785/0120040154

Crone, A.J., Personius, S.F., Craw, P.A., Haeussler, P.J. \& Staft, L.A. (2004) The susitna glacier thrust fault: Characteristics of surface ruptures on the fault that initiated the 2002 denali fault earthquake. Bull. Seismol. Soc. Am., 94, 5-22. doi:10.1785/0120040619

Das, S. \& Kostrov, B. V. (1990) Inversion for seismic slip rate history and distribution with stabilizing constraints: Application to the 1986 Andreanof Islands Earthquake. J. Geophys. Res., 95, 6899, John Wiley \& Sons, Ltd. doi:10.1029/JB095iB05p06899

Dreger, D.S., Oglesby, D.D., Harris, R., Ratchkovski, N. \& Hansen, R. (2004) Kinematic and dynamic rupture models of the November 3, 2002 Mw7.9 Denali, Alaska, earthquake. Geophys. Res. Lett., 31, 2-5. doi:10.1029/2003GL018333

Dunham, E.M. \& Archuleta, R.J. (2004) Evidence for a supershear transient during the 2002 Denali fault earthquake. Bull. Seismol. Soc. Am., 94, 256-268. doi:10.1785/0120040616

Duputel, Z., Agram, P.S., Simons, M., Minson, S.E. \& Beck, J.L. (2014) Accounting for prediction uncertainty when inferring subsurface fault slip. Geophys. J. Int., 197, 464-482, Oxford Academic. doi:10.1093/gji/ggt517

Dziewonski, A.M., Chou, T.-A. \& Woodhouse, J.H. (1981) Determination of earthquake source parameters from waveform data for studies of global and regional seismicity. J. Geophys. Res. Solid Earth, 86, 2825-2852, John Wiley \& Sons, Ltd. doi:10.1029/JB086iB04p02825 
Eberhart-Phillips, D., Haeussler, P.J., Freymueller, J.T., Frankel, A.D., Rubin, C.M., Craw, P., Ratchkovski, N.A., et al. (2003) The 2002 Denali fault earthquake, Alaska: A large magnitude, slip-partitioned event. Science (80-. )., 300, 11131118. doi:10.1126/science. 1082703

Ekström, G., Nettles, M. \& Dziewoński, A.M. (2012) The global CMT project 20042010: Centroid-moment tensors for 13,017 earthquakes. Phys. Earth Planet. Inter., 200-201, 1-9, Elsevier. doi:10.1016/j.pepi.2012.04.002

Ellsworth, W.L., Celebi, M., Evans, J.R., Jensen, E.G., Kayen, R., Metz, M.C., Nyman, D.J., et al. (2004) Near-field ground motion of the 2002 Denali fault, Alaska, earthquake recorded at pump station 10. Earthq. Spectra, 20, 597-615. doi:10.1193/1.1778172

Feng, G., Hetland, E.A., Ding, X., Li, Z. \& Zhang, L. (2010) Coseismic fault slip of the $2008 \mathrm{M}$ w 7.9 Wenchuan earthquake estimated from InSAR and GPS measurements. Geophys. Res. Lett., 37, n/a-n/a. doi:10.1029/2009GL041213

Fielding, E.J., Sladen, A., Li, Z., Avouac, J.P., Bürgmann, R. \& Ryder, I. (2013) Kinematic fault slip evolution source models of the 2008 M7.9 wenchuan earthquake in china from SAR interferometry, GPS and teleseismic analysis and implications for longmen shan tectonics. Geophys. J. Int., 194, 1138-1166. doi:10.1093/gji/ggt155

Frankel, A. (2004) Rupture Process of the M 7.9 Denali Fault, Alaska, Earthquake: Subevents, Directivity, and Scaling of High-Frequency Ground Motions. Bull. Seismol. Soc. Am., 94, S234-S255. doi:10.1785/0120040612

Fukahata, Y., Nishitani, A. \& Matsu'ura, M. (2004) Geodetic data inversion using $\mathrm{ABIC}$ to estimate slip history during one earthquake cycle with viscoelastic slipresponse functions. Geophys. J. Int., 156, 140-153. doi:10.1111/j.1365246X.2004.02122.x 
Fukahata, Y., Yagi, Y. \& Matsu'ura, M. (2003) Waveform inversion for seismic source processes using ABIC with two sorts of prior constraints: Comparison between proper and improper formulations. Geophys. Res. Lett., 30, 1-4. doi:10.1029/2002GL016293

Fukahata, Y., Yagi, Y. \& Rivera, L. (2014) Theoretical relationship between backprojection imaging and classical linear inverse solutions. Geophys. J. Int., 196, 552-559. doi:10.1093/gji/ggt392

GEBCO Bathymetric Compilation Group 2020. (2020) GEBCO_2020 Grid. doi:10.5285/a29c5465-b138-234d- e053-6c86abc040b9

Haeussler, P.J., Schwartz, D.P., Dawson, T.E., Stenner, H.D., Lienkaemper, J.J., Sherrod, B., Cinti, F.R., et al. (2004) Surface rupture and slip distribution of the Denali and totschunda faults in the 3 November 2002 M 7.9 earthquake, Alaska. Bull. Seismol. Soc. Am., 94, 23-52. doi:10.1785/0120040626

Hartzell, S., Mendoza, C., Ramirez-Guzman, L., Zeng, Y. \& Mooney, W. (2013) Rupture History of the $2008 \mathrm{M}$ w 7.9 Wenchuan, China, Earthquake: Evaluation of Separate and Joint Inversions of Geodetic, Teleseismic, and Strong-Motion Data. Bull. Seismol. Soc. Am., 103, 353-370. doi:10.1785/0120120108

Hartzell, S.H. \& Heaton, T.H. (1983) Inversion of strong ground motion and teleseismic waveform data for the fault rupture history of the 1979 Imperial Valley, California, earthquake. Bull. Seismol. Soc. Am., 73, 1553-1583. Retrieved from https://pubs.geoscienceworld.org/ssa/bssa/article/73/6A/1553/118510

Hashimoto, M., Fukushima, Y. \& Fukahata, Y. (2011) Fan-delta uplift and mountain subsidence during the Haiti 2010 earthquake. Nat. Geosci., 4, 255-259, Nature Publishing Group. doi:10.1038/ngeo1115 
Hayes, G.P., Briggs, R.W., Sladen, A., Fielding, E.J., Prentice, C., Hudnut, K., Mann, P., et al. (2010) Complex rupture during the 12 January 2010 Haiti earthquake. Nat. Geosci., 3, 800-805, Nature Publishing Group. doi:10.1038/ngeo977

Hicks, S.P., Okuwaki, R., Steinberg, A., Rychert, C.A., Harmon, N., Abercrombie, R.E., Bogiatzis, P., et al. (2020) Back-propagating supershear rupture in the 2016 Mw 7.1 Romanche transform fault earthquake. Nat. Geosci., 13, 647-653, Nature Research. doi:10.1038/s41561-020-0619-9

Ji, C., Helmberger, D. V. \& Wald, D.J. (2004) A teleseismic study of the 2002 Denali fault, Alaska, earthquake and implications for rapid strong-motion estimation. Earthq. Spectra, 20, 617-637. doi:10.1193/1.1778388

Kikuchi, M. \& Kanamori, H. (1991) Inversion of complex body waves - III. Bull. Seismol. Soc. Am., 81, 2335-2350. Retrieved from https://pubs.geoscienceworld.org/ssa/bssa/article/81/6/2335/102472

Koehler, R.D., Farrell, R.-E., Burns, P.A.C. \& Combellick, R.A. (2012) Quaternary faults and folds in Alaska: A digital database. Alaska Div. Geol. Geophys. Surv. Fairbanks, AK, USA. doi:10.14509/23944

Laske, G., Masters, G., Ma, Z. \& Pasyanos, M. (2013) Update on CRUST1.0---A 1degree global model of Earth's crust. EGU Gen. Assem. 2013, 15, 2658. Retrieved from http://meetingorganizer.copernicus.org/EGU2013/EGU2013-2658.pdf

Lay, T., Ye, L., Bai, Y., Cheung, K.F. \& Kanamori, H. (2018) The $2018<$ scp $>M{ }_{W}$ $</$ scp $>7.9$ Gulf of Alaska Earthquake: Multiple Fault Rupture in the Pacific Plate. Geophys. Res. Lett., 45, 9542-9551. doi:10.1029/2018GL079813

Liu-Zeng, J., Zhang, Z., Wen, L., Tapponnier, P., Sun, J., Xing, X., Hu, G., et al. (2009) Co-seismic ruptures of the 12 May 2008, Ms 8.0 Wenchuan earthquake, Sichuan: East-west crustal shortening on oblique, parallel thrusts along the eastern edge of 
Tibet. Earth Planet. Sci. Lett., 286, 355-370, Elsevier B.V. doi:10.1016/j.eps1.2009.07.017

Madariaga, R. (1977) High-frequency radiation from crack (stress drop) models of earthquake faulting. Geophys. J. Int., 51, 625-651. doi:10.1111/j.1365246X.1977.tb04211.x

Meng, L., Ampuero, J.P., Stock, J., Duputel, Z., Luo, Y. \& Tsai, V.C. (2012) Earthquake in a Maze: Compressional Rupture Branching During the $2012 \mathrm{Mw} 8.6$ Sumatra Earthquake. Science (80-. )., 337, 724-726. doi:10.1126/science.1224030

Minson, S.E., Simons, M. \& Beck, J.L. (2013) Bayesian inversion for finite fault earthquake source models I-theory and algorithm. Geophys. J. Int., 194, 17011726, Oxford Academic. doi:10.1093/gji/ggt180

Nakamura, T., Tsuboi, S., Kaneda, Y. \& Yamanaka, Y. (2010) Rupture process of the 2008 Wenchuan, China earthquake inferred from teleseismic waveform inversion and forward modeling of broadband seismic waves. Tectonophysics, 491, 72-84, Elsevier B.V. doi:10.1016/j.tecto.2009.09.020

Okuwaki, R. \& Yagi, Y. (2018) Role of geometric barriers in irregular-rupture evolution during the 2008 Wenchuan earthquake. Geophys. J. Int., 212, 16571664. doi:10.1093/gji/ggx502

Okuwaki, Ryo, Hirano, S., Yagi, Y.\& Shimizu, K. (2020) Inchworm-like source evolution through a geometrically complex fault fueled persistent supershear rupture during the 2018 Palu Indonesia earthquake. Earth Planet. Sci. Lett., 547, 116449, Elsevier B.V. doi:10.1016/j.eps1.2020.116449

Okuwaki, Ryo, Yagi, Y. \& Hirano, S. (2015) Relationship between High-frequency Radiation and Asperity Ruptures, Revealed by Hybrid Back-projection with a Nonplanar Fault Model. Sci. Rep., 4, 7120. doi:10.1038/srep07120 
Prentice, C.S., Mann, P., Crone, A.J., Gold, R.D., Hudnut, K.W., Briggs, R.W., Koehler, R.D., et al. (2010) Seismic hazard of the Enriquillo-Plantain Garden fault in Haiti inferred from palaeoseismology. Nat. Geosci., 3, 789-793, Nature Publishing Group. doi:10.1038/ngeo991

Ragon, T., Sladen, A. \& Simons, M. (2018) Accounting for uncertain fault geometry in earthquake source inversions - I: theory and simplified application. Geophys. J. Int., 214, 1174-1190, Oxford University Press. doi:10.1093/gji/ggy187

Shen, Z.-K., Sun, J., Zhang, P., Wan, Y., Wang, M., Bürgmann, R., Zeng, Y., et al. (2009) Slip maxima at fault junctions and rupturing of barriers during the 2008 Wenchuan earthquake. Nat. Geosci., 2, 718-724, Nature Publishing Group. doi:10.1038/ngeo636

Shimizu, K., Yagi, Y., Okuwaki, R. \& Fukahata, Y. (2020) Development of an inversion method to extract information on fault geometry from teleseismic data. Geophys. J. Int., 220, 1055-1065, Oxford University Press. doi:10.1093/gji/ggz496

Tadapansawut, T., Okuwaki, R., Yagi, Y. \& Yamashita, S. (2021) Rupture Process of the 2020 Caribbean Earthquake Along the Oriente Transform Fault, Involving Supershear Rupture and Geometric Complexity of Fault. Geophys. Res. Lett., 48, 1-9. doi:10.1029/2020GL090899

U.S. Geological Survey Earthquake Hazards Program. (2017) Advanced National Seismic System (ANSS) Comprehensive Catalog of Earthquake Events and Products. doi:https://doi.org/10.5066/F7MS3QZH

Walker, K.T. \& Shearer, P.M. (2009) Illuminating the near-sonic rupture velocities of the intracontinental Kokoxili M w 7.8 and Denali fault M w 7.9 strike-slip earthquakes with global P wave back projection imaging. J. Geophys. Res., 114, B02304. doi:10.1029/2008JB005738 
Xu, X., Wen, X., Yu, G., Chen, G., Klinger, Y., Hubbard, J. \& Shaw, J. (2009)

Coseismic reverse- and oblique-slip surface faulting generated by the $2008 \mathrm{Mw} 7.9$ Wenchuan earthquake, China. Geology, 37, 515-518. doi:10.1130/G25462A.1

Yabuki, T. \& Matsu'ura, M. (1992) Geodetic data inversion using a Bayesian information criterion for spatial distribution of fault slip. Geophys. J. Int., 109, 363-375, Oxford Academic. doi:10.1111/j.1365-246X.1992.tb00102.x

Yagi, Y. (2004) Source Rupture Process of the Tecoman, Colima, Mexico Earthquake of 22 January 2003, Determined by Joint Inversion of Teleseismic Body-Wave and Near-Source Data. Bull. Seismol. Soc. Am., 94, 1795-1807. doi:10.1785/012003095

Yagi, Y. \& Fukahata, Y. (2011) Introduction of uncertainty of Green's function into waveform inversion for seismic source processes. Geophys. J. Int., 186, 711-720, Oxford Academic. doi:10.1111/j.1365-246X.2011.05043.x

Yagi, Y., Nakao, A. \& Kasahara, A. (2012) Smooth and rapid slip near the Japan Trench during the 2011 Tohoku-oki earthquake revealed by a hybrid backprojection method. Earth Planet. Sci. Lett., 355-356, 94-101, Elsevier. doi:10.1016/j.eps1.2012.08.018

Yagi, Y., Nishimura, N. \& Kasahara, A. (2012) Source process of the 12 May 2008 Wenchuan, China, earthquake determined by waveform inversion of teleseismic body waves with a data covariance matrix. Earth, Planets Sp., 64, e13-e16. doi:10.5047/eps.2012.05.006

Yamashita, S., Yagi, Y., Okuwaki, R., Shimizu, K., Agata, R. \& Fukahata, Y. (2021) Consecutive ruptures on a complex conjugate fault system during the 2018 Gulf of Alaska earthquake. Sci. Rep., 11, 5979, Earth and Space Science Open Archive. doi:10.1038/s41598-021-85522-w 
This is a non-peer reviewed EarthArXiv preprint 


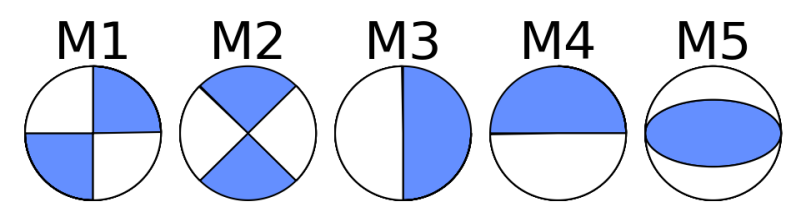

Figure 1. Five basis double-couple components (Kikuchi \& Kanamori 1991) used in the potency density tensor inversion method. 
(a)

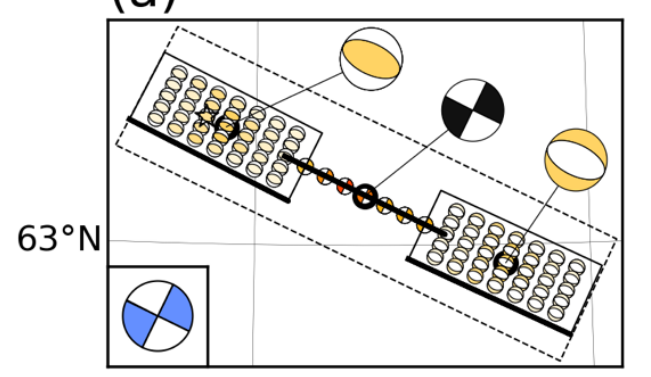

(c)

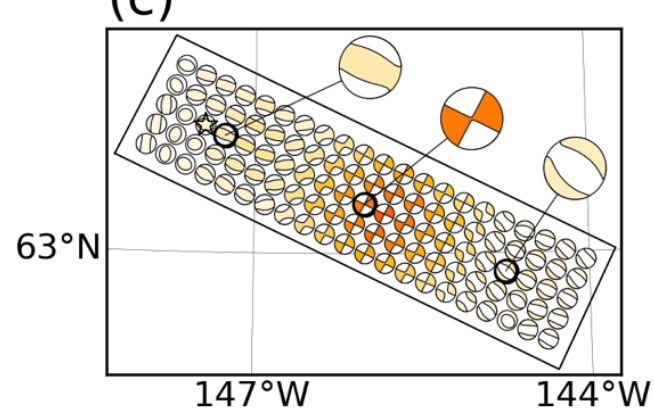

(b)

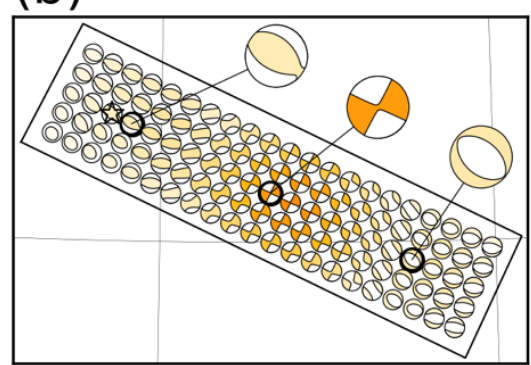

(d)

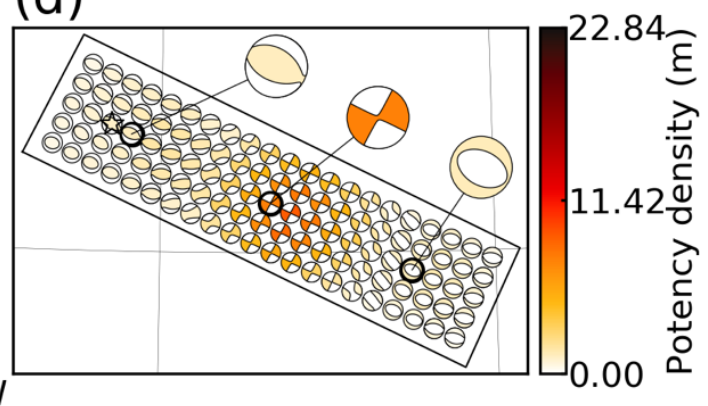

Figure 2. Input source model and resultant potency density tensor distributions in the numerical experiment. (a) Input slip tensor distribution. The input faults consist of reverse, right-lateral strike-slip, and normal faults. The reverse and normal faults dip $45^{\circ}$ to the northeast, and the strike-slip fault is vertical. The top of each fault plane is shown by a bold line. The dashed rectangle shows the assumed horizontal model plane used in the potency density tensor inversion analysis. Inset beachball shows the total moment tensor. (b), (c) and (d) show the potency density tensor distribution obtained by the unweighted, moment-tensor-weighted, and time-adaptive smoothing constraints, respectively. The rectangle outlines the assumed model plane. The star denotes the hypocenter. Some beachballs with black outline have been selected and enlarged to highlight the spatial variation of the focal mechanism. 


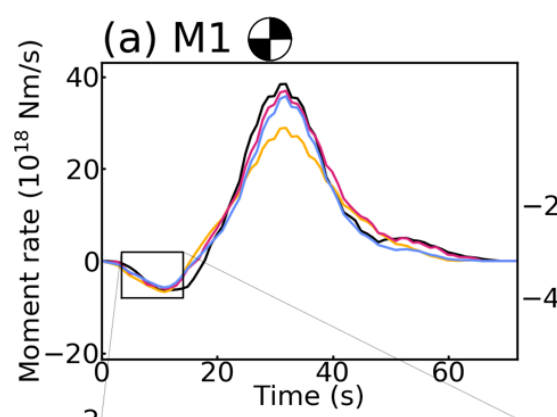

(b) M2
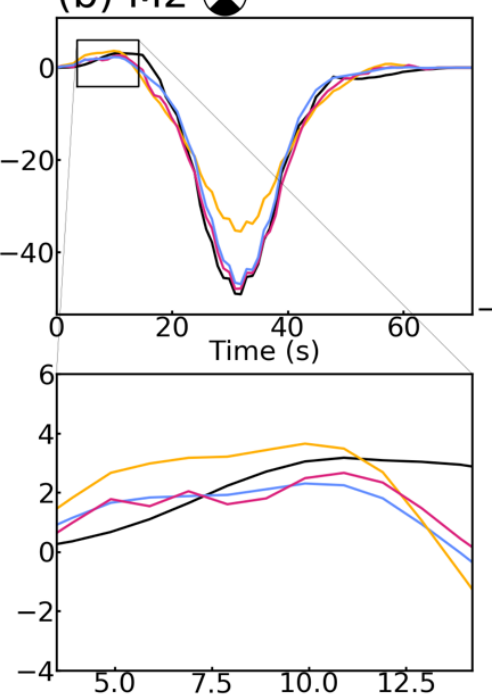

(c) M5

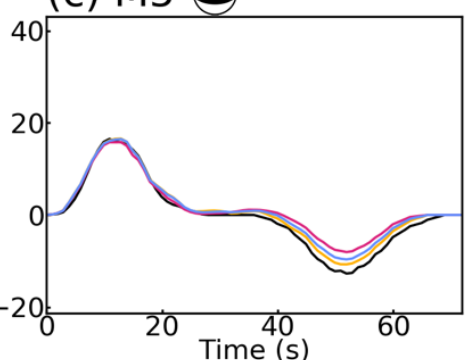

- Input

Unweighted

Moment-tensor-weighted

Time-adaptive

Figure 3. Comparison of input and resultant moment rate functions in the numerical experiment. (a), (b) and (c) represent the moment rate functions of the M1, M2 and M5 slip components (Kikuchi \& Kanamori 1991), respectively. The color legend for each trace is shown at the bottom right. The rectangular ranges in (a) and (b) are enlarged at the bottom of each panel to see the wriggling of the trace obtained with the momenttensor-weighted smoothing constraint. 


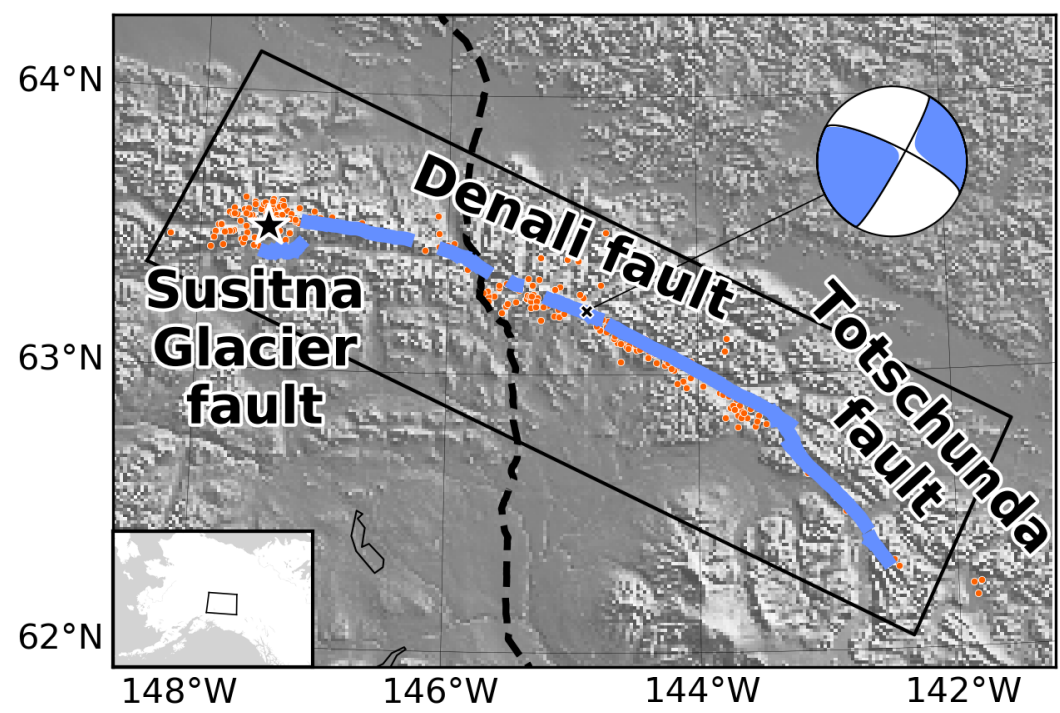

Figure 4. Overview of the source region of the 2002 Denali fault earthquake. The star indicates the epicenter and the orange dots are aftershocks $(\boldsymbol{M} \geq \mathbf{3 . 5}, 3-9$ November 2002) (U.S. Geological Survey Earthquake Hazards Program 2017). The beachball shows the GCMT solution (Dziewonski et al. 1981, Ekström et al. 2012) and is connected to its centroid position indicated by the cross mark. The rectangle outlines the model plane. The blue lines represent well-constrained faults that have been active for less than 150 years (Koehler et al. 2012). The dashed line shows the route of the TransAlaska Pipeline System (TAPS). The background topography is derived from the GEBCO 2020 Grid (GEBCO Bathymetric Compilation Group 2020 2020). The inset map shows the regional settings. 

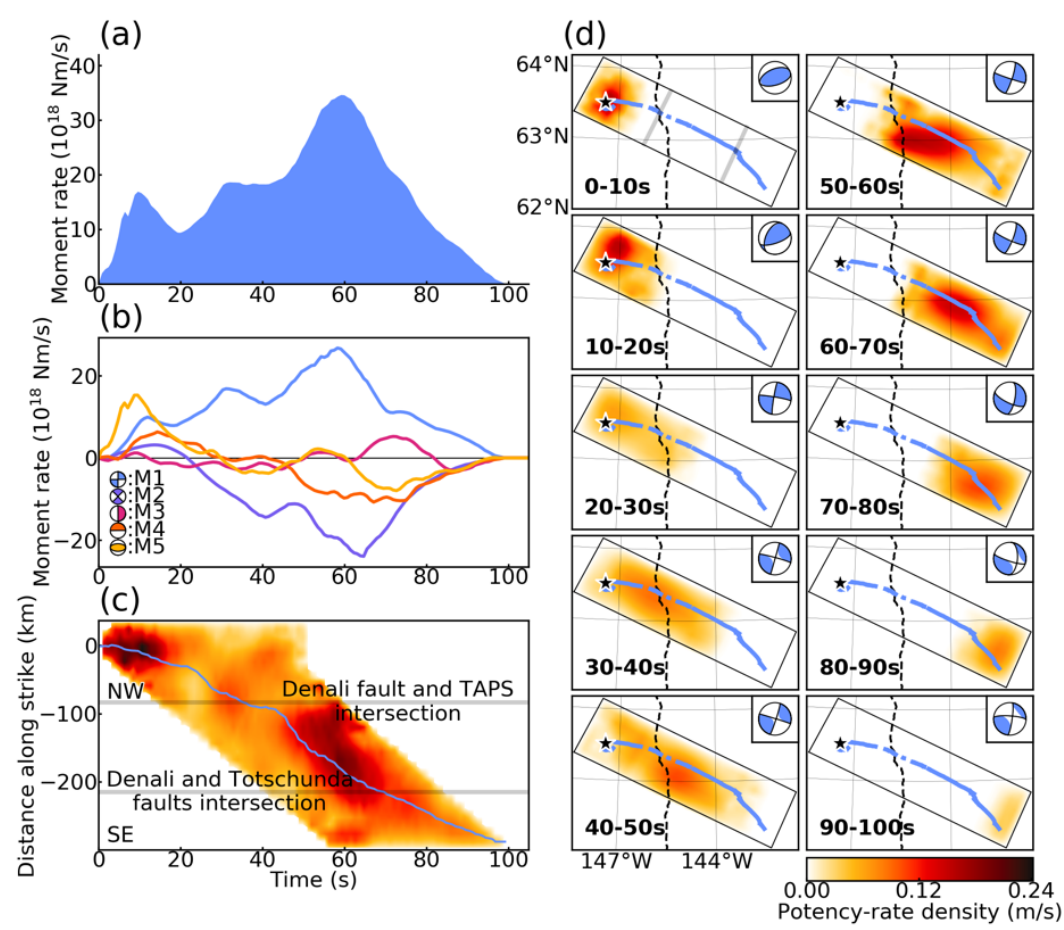

(e)

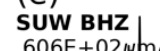

$.606 \mathrm{E}+02 \mathrm{pm} / \mathrm{s}$

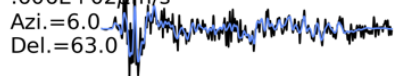

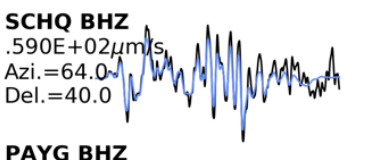

PAYG BHZ

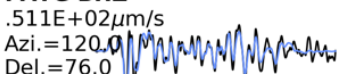

(O)

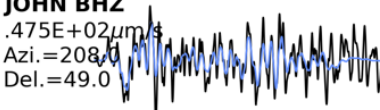

DAV BHZ

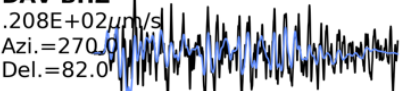

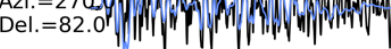

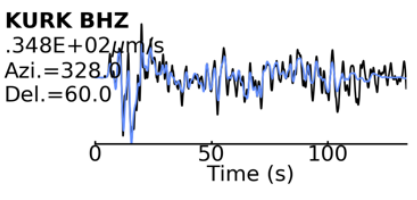

Figure 5. Inversion results with the time-adaptive smoothing constraint for the 2002

Denali fault earthquake. (a) The moment rate function. (b) The moment rate function for each basis double-couple component. The color legend for each trace is shown in bottom-left. (c) Time evolution of the potency-rate density, projected along the strike direction of the assumed model plane. The horizontal lines indicate the intersection of the Denali fault and the TAPS, and the junction of the Denali and Totschunda faults from top to bottom, respectively. The map projection of these intersections is shown in the upper left panel of (d). The blue line represents a trace of the centroid position of the potency-rate density. (d) Snapshot of the potency-rate density. The corresponding time for each snapshot is noted at the bottom-left of each panel. The star indicates the epicenter, and the rectangle outlines the model plane. The blue lines represent fault lines (Koehler et al. 2012), and the dashed line shows route of the TAPS. The inset beachball in each panel indicates the corresponding moment tensor at each time period. (e) Comparison of observed waveforms (black) with synthetic waveforms (blue) at selected stations. Each panel is labeled with the station name, maximum amplitude, azimuth 
(Azi.), and epicentral distance (Del.) from the mainshock. All observed waveforms were resampled to $20 \mathrm{~Hz}$ for plotting. 


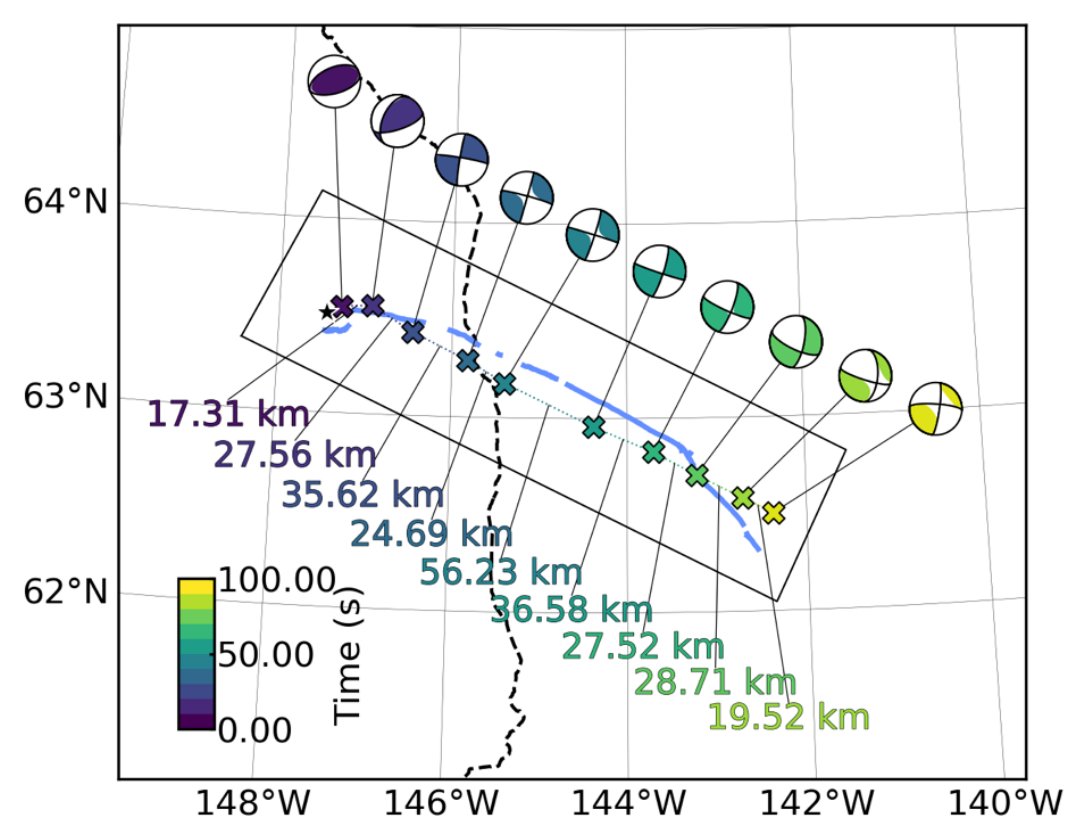

Figure 6. Migration of the moment tensor every $10 \mathrm{~s}$ for the 2002 Denali fault earthquake obtained by applying the time-adaptive smoothing constraint. The crosses indicate the average centroid location and are linked to the corresponding moment tensor. The neighboring centroid locations are connected by a dotted line to indicate their distance. 


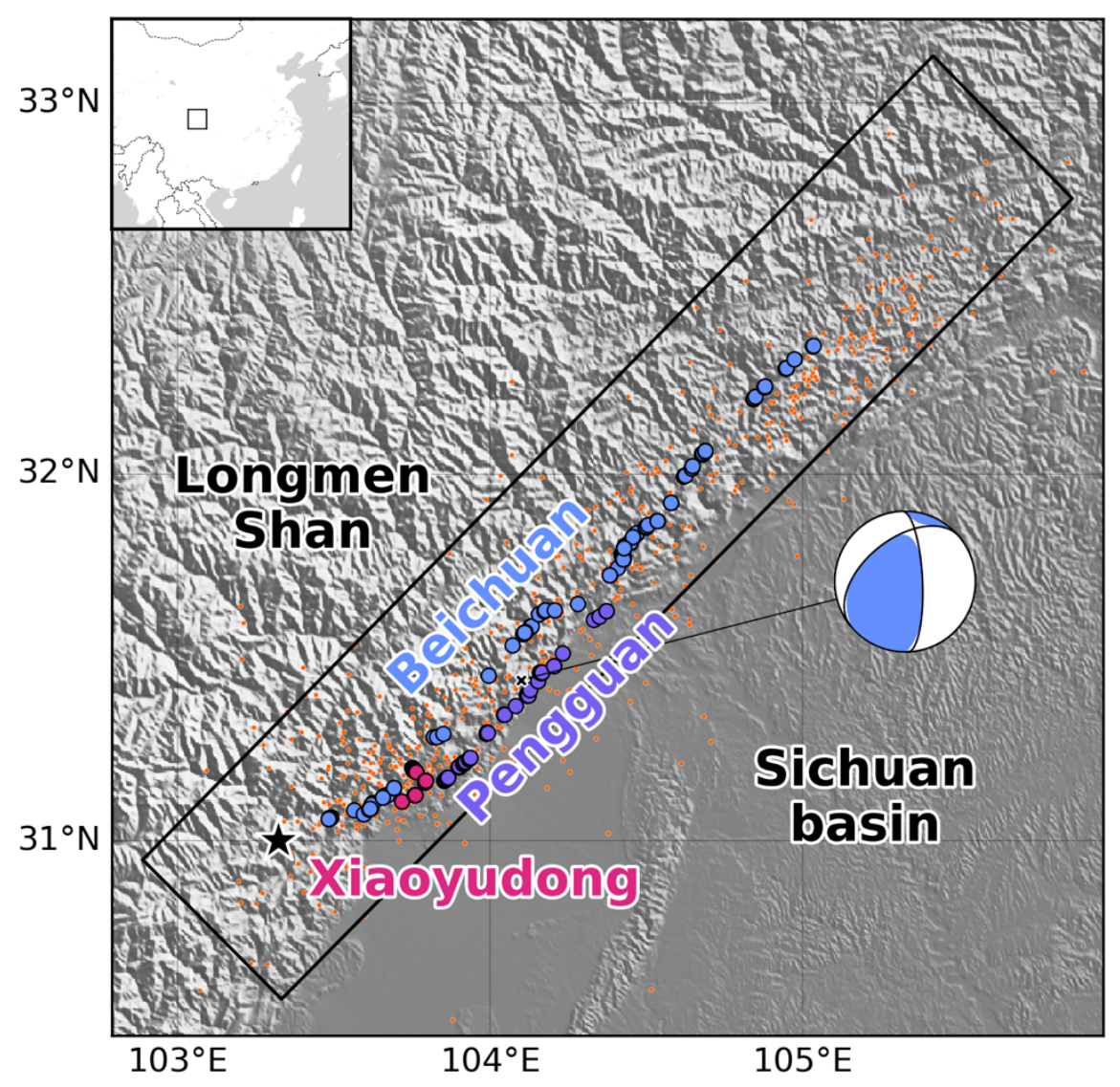

Figure 7. Overview of the source region of the 2008 Wenchuan earthquake. The star indicates the epicenter and the orange dots are aftershocks ( $\boldsymbol{M} \geq \mathbf{3 . 5}, 12-18$ May 2008) (U.S. Geological Survey Earthquake Hazards Program 2017). The beachball shows the GCMT solution (Dziewonski et al. 1981, Ekström et al. 2012) and is connected to its centroid position indicated by the cross mark. The rectangle outlines the model plane. The large dots represent surface rupture along the Beichuan, Pengguan and Xiaoyudong faults (Xu et al. 2009), color-coded for each fault. The background topography is derived from the GEBCO 2020 Grid (GEBCO Bathymetric Compilation Group 2020 2020). The inset map shows the regional setting. 
(a)

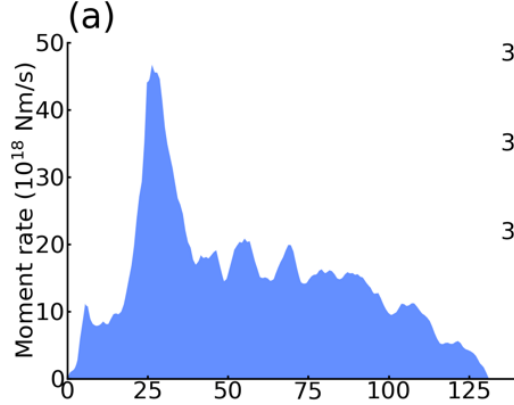

(b)

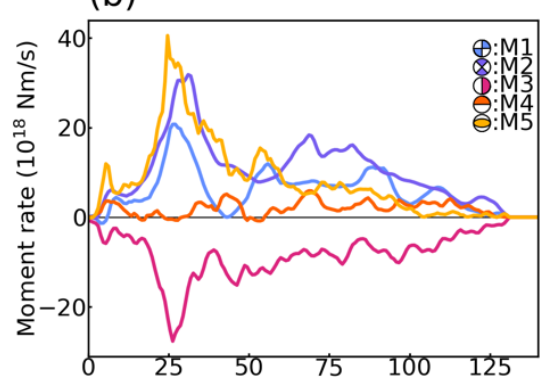

(c)

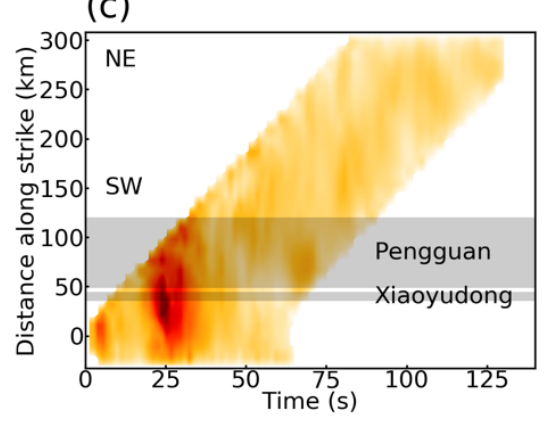

(d)
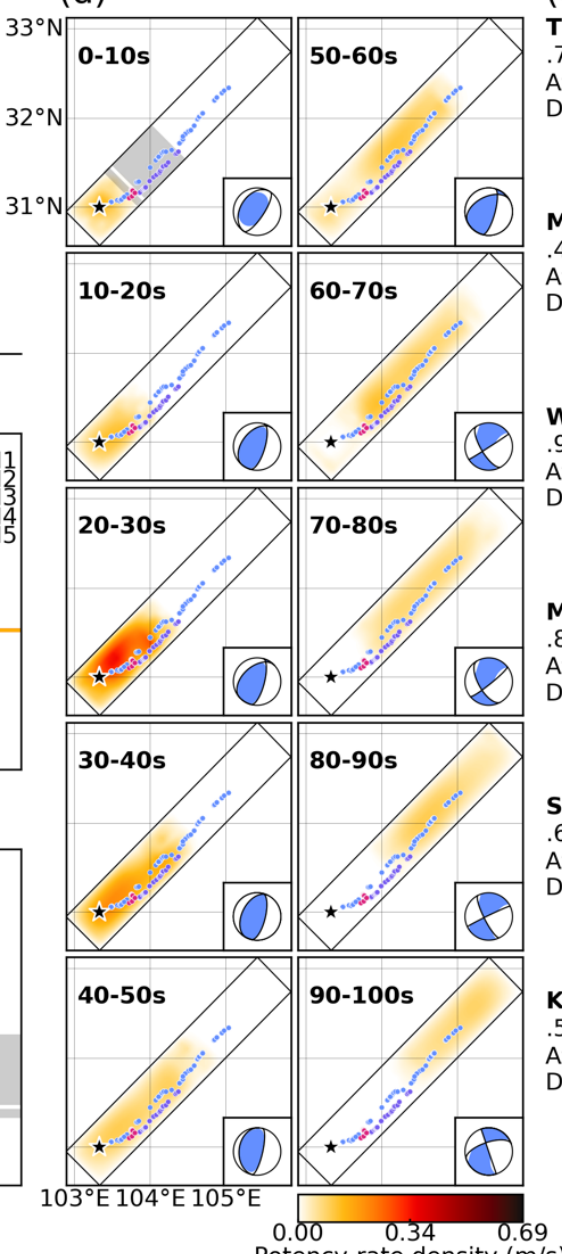

(e)

TIXI BHZ

$.748 \mathrm{E}+02 \mu \mathrm{m} / \mathrm{s}$ Azi. $=12.0$
Del. $=43.0, N$

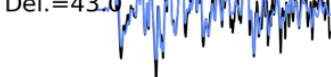

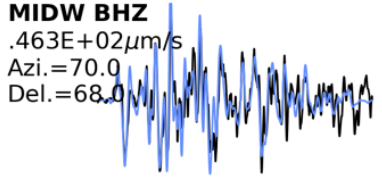

WRAB BHZ

$.941 \mathrm{E}+02 \mu \mathrm{m}$

Azi. $=146.9$
Del. $=59.9$

Del. =59.0 N

MSEY BHZ

$820 \mathrm{E}+02 \mu \mathrm{m} / \mathrm{s}$

Azi. $=241,0$

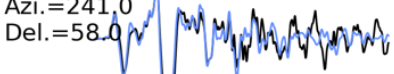

SSB BHZ

$.616 \mathrm{E}+02 \mu \mathrm{m} / \mathrm{s}$

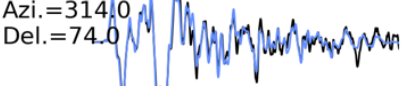

KEV BHZ

$548 \mathrm{E}+02 \mu \mathrm{m}$

Azi. $=336.01$
Del. $=57.0 .01$

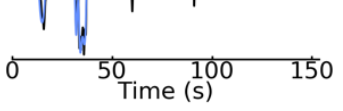

Figure 8. Inversion results with the time-adaptive smoothing constraint for the 2008 Wenchuan earthquake. (a) The moment rate function. (b) The moment rate function for each basis double-couple component. The color legend for each trace is shown in topright. (c) Time evolution of the potency-rate density, projected along the strike direction of the assumed model plane. The shaded areas indicate the Pengguan and Xiaoyudong fault zones, projected along the assumed model plane strike. The map projection of these shaded areas is shown in the upper left panel of (d). (d) Snapshot of the potencyrate density. The corresponding time for each snapshot is noted at the top-left of each panel. The star indicates the epicenter, and the rectangle outlines the model plane. The dots represent surface rupture (Xu et al. 2009). The inset beachball in each panel indicates the corresponding moment tensor at each time. (e) Comparison of observed 
waveforms (black) with synthetic waveforms (blue) at the selected stations. Each panel is labeled with the station name, maximum amplitude, azimuth (Azi.), and epicentral distance (Del.) from the mainshock. All observed waveforms were resampled to $20 \mathrm{~Hz}$ for plotting. 
(a)

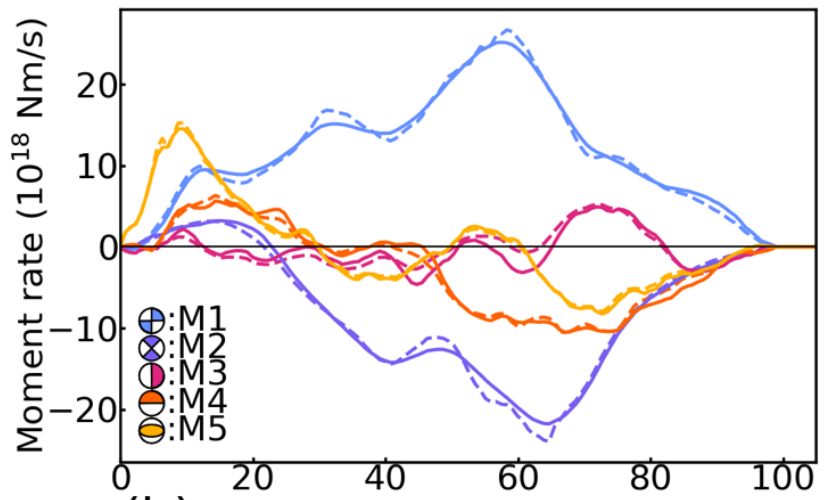

(b)

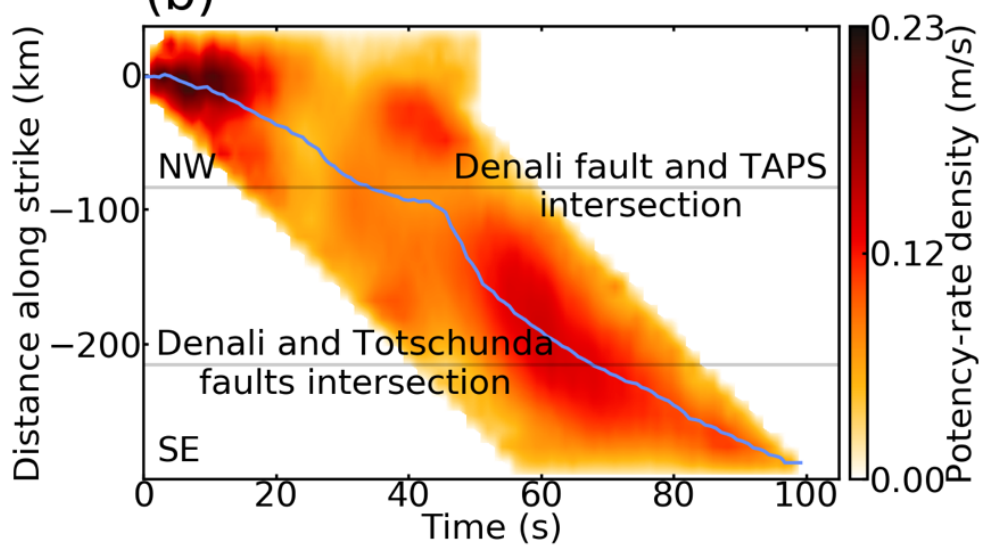

Figure 9. Inversion results with the unweighted smoothing constraints for the 2002 Denali fault earthquake. (a) Comparison of the moment rate functions for each basis double-couple component with the unweighted (solid lines) and the time-adaptive (dashed lines) smoothing constraints. The color legend for each trace is shown in bottom-left. (b) Time evolution of the potency-rate density obtained with the unweighted smoothing constraint. The result is projected along the strike direction of the assumed model plane. The horizontal lines indicate the intersection of the Denali fault and the TAPS, and the junction of the Denali and Totschunda faults from top to bottom, respectively. The blue line represents the trace of the centroid position of the potency-rate density. 
(a)

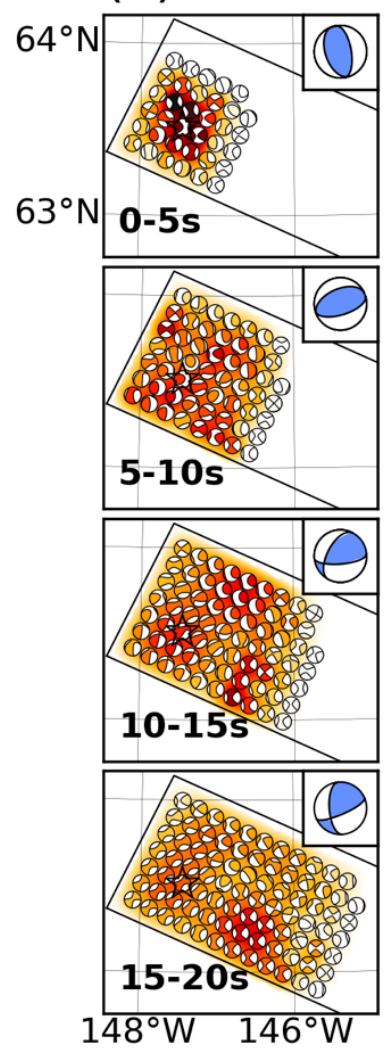

(b)
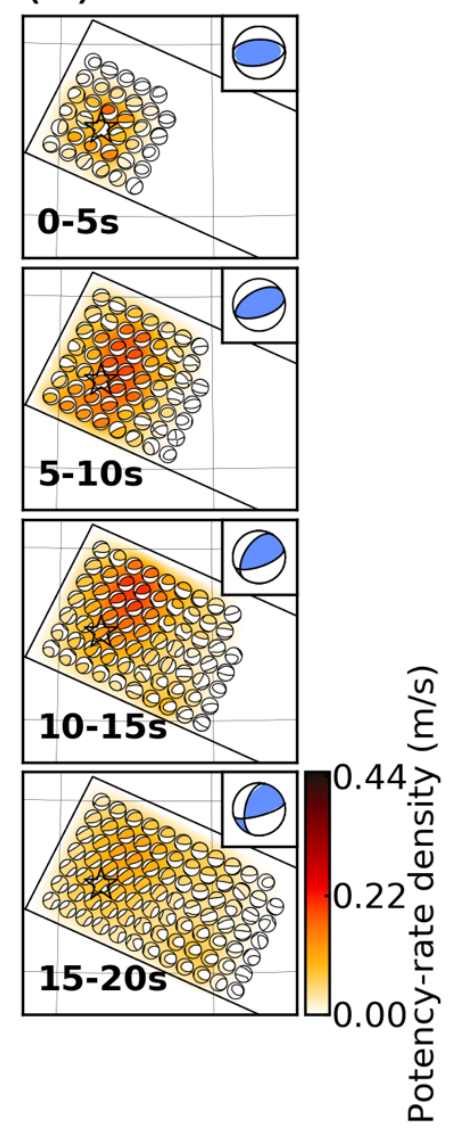

Figure 10. Comparison of snapshots obtained with (a) the moment-tensor-weighted and (b) time-adaptive smoothing constraints for the 2002 Denali fault earthquake. The time period for each snapshot is noted at the bottom-left of each panel. The star indicates the epicenter, and the rectangle outlines the model plane. The inset beachball in each panel indicates the corresponding moment tensor at each time period. 

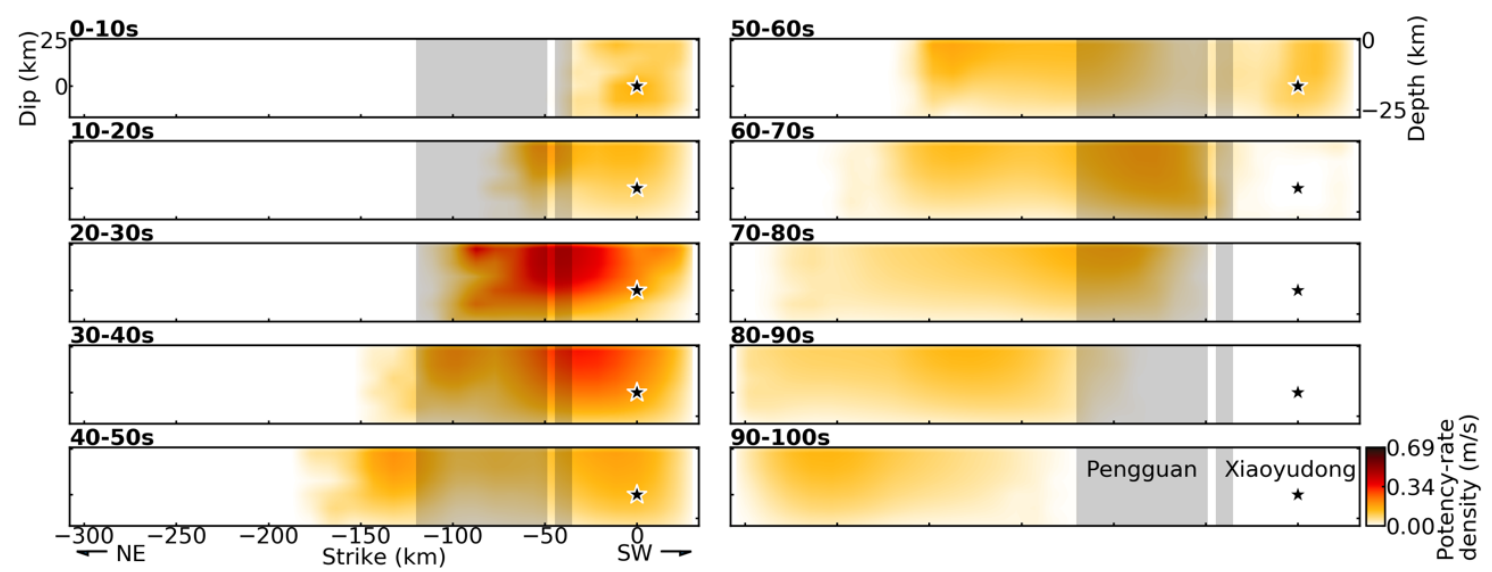

Figure 11. Snapshots of the potency-rate density for the 2008 Wenchuan earthquake along the inclined model plane. The corresponding time for each snapshot is noted at the upper left of each panel. The star indicates the hypocenter. The shaded areas indicate the Pengguan and Xiaoyudong fault zones, projected along the strike direction of the assumed model plane. The color bar used in this figure is the same as in Fig. 8. 